\title{
Orestes Foresto Neto
}

\section{A ativação do sistema NF-kappa B promove inflamação e lesão glomerular na doença renal diabética experimental}

Tese apresentada à Faculdade de Medicina da Universidade de São Paulo para obtenção do título de Doutor em Ciências

Programa de Nefrologia

Orientador: Prof. Dr. Roberto Zatz

São Paulo 


\section{Orestes Foresto Neto}

\section{A ativação do sistema NF-kappa B promove inflamação e lesão glomerular na doença renal diabética experimental}

Tese apresentada à Faculdade de Medicina da Universidade de São Paulo para obtenção do título de Doutor em Ciências

Programa de Nefrologia

Orientador: Prof. Dr. Roberto Zatz

São Paulo 


\section{Dados Internacionais de Catalogação na Publicação (CIP)}

Preparada pela Biblioteca da

Faculdade de Medicina da Universidade de São Paulo

Creprodução autorizada pelo autor

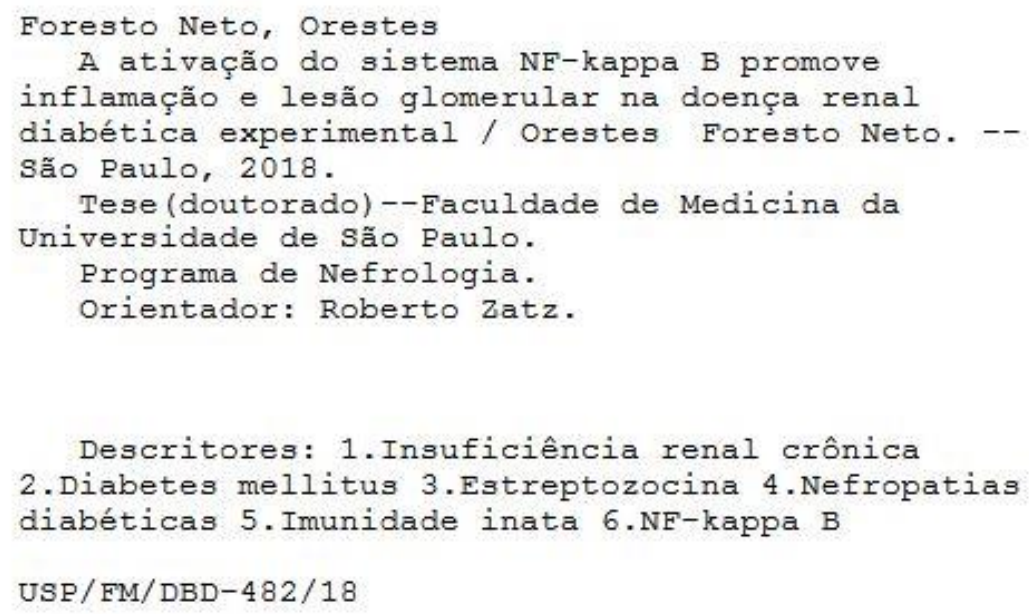

Responsável: Erinalva da Conceição Batista, CRB-8 6755 
Dedico esta tese à minha amada família, Silvana, Orestes e Silvia, e aos meus mestres da vida, Clarice e Roberto. Vocês estarão sempre no meu coração! 


\section{AGRADECIMENTOS}

Quero agradecer ao meu orientador Prof Dr Roberto Zatz por todos os ensinamentos, pela compreensão e pela dedicação em auxiliar no desenvolvimento deste trabalho. Obrigado por me orientar e um por ser um exemplo de pesquisador e professor para todos nós.

À Dra Clarice Kazue Fujihara, que me acolheu e me guiou desde o início de minha carreira na pesquisa. Sua valiosa amizade, sua ajuda, seu carinho e seus grandiosos ensinamentos foram fundamentais para as minhas conquistas profissionais e para minha formação. Só tenho a Ihe agradecer por tudo!!!

Ao Prof Dr Niels Olsen Saraiva Câmara pela colaboração, pela amizade, pelas sugestões brilhantes e pelo apoio no desenvolvimento deste trabalho e em outras de minhas conquistas.

Ao Prof Dr Hans-Joachim Anders, que me recebeu com muito entusiasmo e me orientou durante meu estágio de pesquisa na Alemanha. Vielen dank!

À Dra Denise Malheiros pela grande colaboração nesse projeto, em especial pelas preciosas análises histológicas.

À Amanda Helen Albino por todo o auxílio no cuidado dos animais e nas demais atividades que resultaram neste trabalho, além de sua grande amizade. Muito obrigado!

À Dra Simone Costa Alarcon Arias por me acompanhar desde a iniciação científica até o doutorado e por me auxiliar na realização deste trabalho. 
Aos meus companheiros de trabalho Victor Ávila, Viviane Faustino, Fernanda Zambom e Marcos Cenedeze pela amizade, pela força e pela colaboração sempre.

Aos alunos de iniciação científica, mestrado, doutorado e aos alumni do LIM16 Raquel, Helena, Gizely, Rafael, Carolina, Flávia Machado, Flávia Fonseca, Sara, Ana, Lisienny e Karin pelo companheirismo.

À Janice Pião e à Claudia Sena pela amizade, pelo apoio técnico e por contribuírem grandemente para a realização deste trabalho.

A todos do LIM16 e do HC, em especial a Ivone, Vagner, Newton, Rosimeire, Luciene, Dra Rosilene, Dra Vanda, Dra Luciene e Dra Rosa pela dedicação e companheirismo.

Aos colegas de trabalho durante meu estágio de pesquisa na LudwigMaximilians-Universität München, em Munique, especialmente Shrikant, Jyaysi, Mohsen, Maciej, Steph, Julian, Santosh, Lidia e Lukas. Thanks guys!

Aos meus amigos e companheiros de vida Lucas, Karine, Otávio, Thiago, Fernanda, Amanda, Jó, Lucia, Rodrigo, Harissa, Ana, Carol, Jéssica, Sirlene, Roberto, Vinícius, William, Eduardo e João. Muito obrigado por fazerem parte da minha vida e pela amizade!

Aos meus pais Silvana e Orestes e à minha irmã Silvia por cuidarem de mim sempre. $O$ apoio financeiro e emocional, o amor e o carinho de vocês foram meu combustível. Amo vocês e sou grato por tudo!

À Fundação de Amparo à Pesquisa do Estado de São Paulo (FAPESP processos no 2013/12256-0, ㄲo 2012/10926-5 e no 2015/24991-1) e ao Conselho Nacional de Desenvolvimento Científico e Tecnológico (CNPq) pelo apoio financeiro que permitiu a realização desta pesquisa e a produção desta tese. 
As histórias que amamos vivem em nós para sempre.

J. K. Rowling 


\section{SUMÁRIO}

LISTA DE ABREVIATURAS

LISTA DE FIGURAS

RESUMO

ABSTRACT

1. INTRODUÇÃO

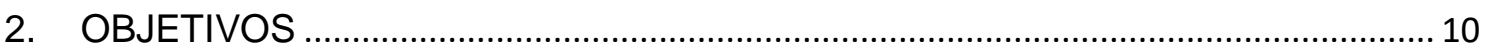

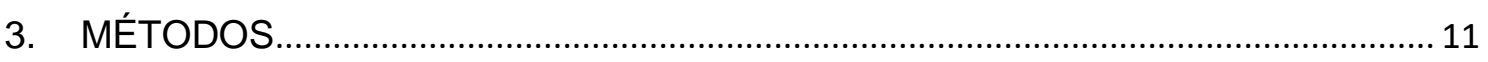

3.1. OBTENÇÃO DO MODELO EXPERIMENTAL ………………………………...... 11

3.2. GRUPOS EXPERIMENTAIS (RESUMO) ………………................................. 12

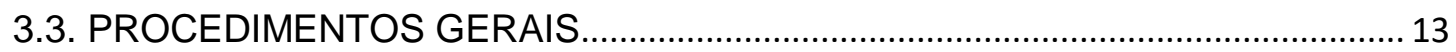

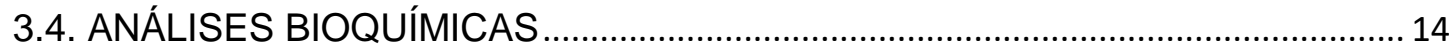

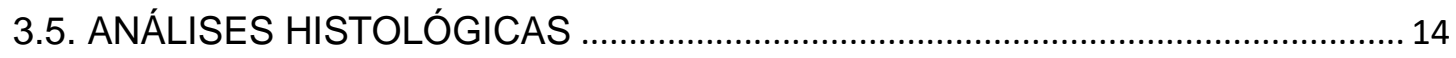

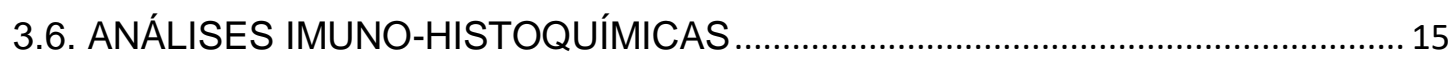

3.7. ESTUDO COM MATERIAL DE BIÓPSIA ………………….................................. 18

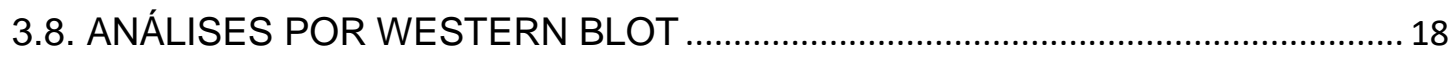

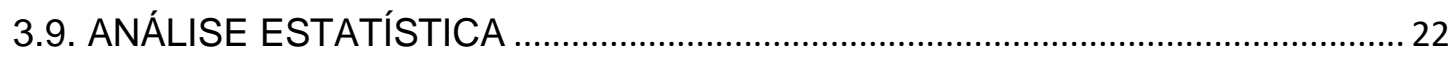

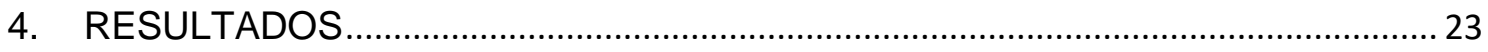

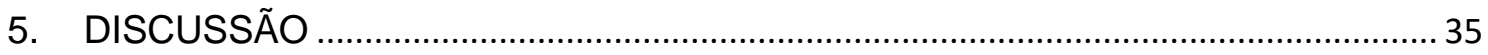

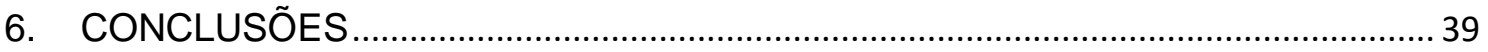

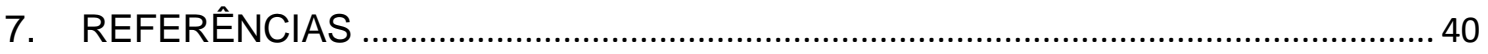




\section{LISTA DE ABREVIATURAS}

$\begin{array}{ll}\text { Abreviatura } & \text { Significado } \\ \text { DRD } & \text { doença renal diabética } \\ \text { DM } & \text { diabetes mellitus } \\ \text { DRC } & \text { doença renal crônica } \\ \text { TGF- } \beta & \text { fator de crescimento e transformação beta } \\ \text { STZ } & \text { estreptozotocina } \\ \text { AGEs } & \text { produtos finais de glicação avançada } \\ \text { RAGEs } & \text { receptores de produtos finais de glicação avançada } \\ \text { RFG } & \text { ritmo de filtração glomerular } \\ \text { PGC } & \text { pressão capilar glomerular } \\ \text { TLRs } & \text { toll-like receptors } \\ \text { PAMP } & \text { pathogen associated molecular pattern } \\ \text { DAMP } & \text { damage associated molecular pattern } \\ \text { HMGB1 } & \text { high mobility group box protein-1 } \\ \text { MyD88 } & \text { myeloid differentiation primary response 88 } \\ \text { NOD } & \text { nucleotide-binding oligomerization domain } \\ \text { NLRs } & \text { NOD-like receptors } \\ & \text { nucleotide-binding oligomerization domain, leucine-rich repeat } \\ \text { NLRP3 } & \text { and pyrin domain containing-3 } \\ \text { ASC } & \text { apoptosis-associated speck-like protein containing a caspase } \\ \text { NF-KB } & \text { recruitment domain adaptor protein } \\ \text { MCP-1 } & \text { nuclear factor-kappa B } \\ \text { IL-6 } & \text { proteína de quimiotaxia para monócitos-1 } \\ \text { PDTC } & \text { interleucina-6 } \\ \text { Nx } & \text { ditiocarbamato de pirrolidina } \\ \text { CN } & \text { ablação renal de 5/6 } \\ \text { \%EG } & \text { controles } \\ \text { Ualb/Ucr } & \text { porcentagem de glomérulos escleróticos } \\ \text { PAS } & \text { relação albumina urinária/creatinina urinária } \\ \text { ZO-1 } & \text { ácido periódico de shiff } \\ \text { HO-1 } & \text { zonula occludens-1 } \\ \text { SOD2 } & \text { heme oxigenase-1 } \\ \text { BSA } & \text { superóxido dismutase 2 } \\ \text { ANOVA } & \text { albumina sérica bovina } \\ & \text { análise de variância } \\ \end{array}$




\section{LISTA DE FIGURAS}

Figura 1. Vias do sistema imune inato .................................................. 5

Figura 2. Glicemia, Ualb/Ucr e EG aos 12 meses......................................... 23

Figura 3. Glicemia, Ualb/Ucr dos grupos DRD- e DRD+.............................. 24

Figura 4. EG e macrófagos dos grupos DRD- e DRD+ ............................. 25

Figura 5. TLR4, p65 e IL-6 dos grupos DRD- e DRD+.............................. 27

Figura 6. NLRP3 dos grupos DRD- e DRD+.......................................... 28

Figura 7. Glicemia, Ualb/Ucr e EG aos 2 meses.......................................... 29

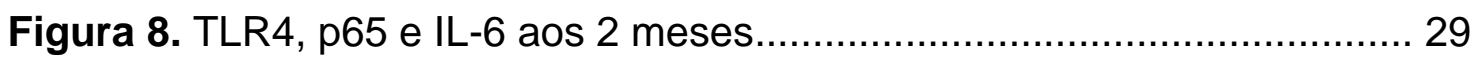

Figura 9. TLR4, p65, IL-6 e HMGB1 - tratamento com PDTC....................... 30

Figura 10. Peso, Glicemia e Ualb/Ucr - tratamento com PDTC..................... 31

Figura 11. EG, ZO-1 e macrófagos - tratamento com PDTC......................... 32

Figura 12. HO-1 e SOD2 - tratamento com PDTC....................................... 33

Figura 13. Tecido renal humano com DRD e normal com IHQ para p65........ 34 


\section{RESUMO}

Foresto Neto O. A ativação do sistema NF-kappa B promove inflamação e lesão glomerular na doença renal diabética experimental [tese]. São Paulo: Faculdade de Medicina, Universidade de São Paulo; 2018.

Altas concentrações de glicose podem ativar a sinalização celular TLR4/NF-kB, desencadeando a produção de mediadores proinflamatórios. Nós investigamos se o sistema NF-KB está envolvido na patogênese e na progressão da doença renal diabética (DRD) experimental, em um modelo de diabetes mellitus (DM) tipo 1 de longa duração. Ratos Munich-Wistar foram tornados diabéticos por uma única injeção de estreptozotocina e foram mantidos moderadamente hiperglicêmicos por meio de injeções diárias de insulina. Após 12 meses, dois subgrupos - progressores e não-progressores - puderam ser formados com base no grau de glomeruloesclerose dos animais diabéticos. Apenas os ratos progressores exibiram ativação renal da via TLR4/NF-kB/LL-6. A ativação dessa via mostrou-se já presente em ratos com DM de curta duração (dois meses), quando a albuminúria e a glomeruloesclerose ainda não são detectáveis. $O$ tratamento crônico com um inibidor do NF-KB, o ditiocarbamato de pirrolidina (PDTC), inibiu a ativação renal da via TLR4/NF-KB/IL-6 nos animais diabéticos, sem interferir em seus níveis glicêmicos. O PDTC preveniu o aumento progressivo da albuminúria, o desenvolvimento de lesões glomerulares/inflamação e o estresse oxidativo renal. A proteína p65, um componente do sistema NF-KB, foi detectada em glomérulos escleróticos e em áreas intersticiais inflamadas de biópsias de pacientes com nefropatia por diabetes tipo 1. Essas observações sugerem que o sistema NF-KB renal desempenha um papel chave no desenvolvimento e na progressão da DRD experimental e pode se tornar um importante alvo terapêutico no esforço para prevenir a progressão da DRD humana.

Descritores: insuficiência renal crônica; diabetes mellitus; estreptozocina; nefropatias diabéticas; imunidade inata; NF-kappa B. 


\begin{abstract}
Foresto Neto O. NF-kappa B activation promotes glomerular injury and inflammation in experimental diabetic kidney [thesis]. São Paulo: "Faculdade de Medicina, Universidade de São Paulo; 2018".

High glucose concentration can activate the TLR4/NF-KB axis, triggering the production of proinflammatory mediators. We investigated whether the NF-kB pathway is involved in the pathogenesis and progression of experimental diabetic kidney disease (DKD) in a model of long-term type 1 diabetes mellitus (DM). Munich-Wistar rats underwent DM by a single streptozotocin injection, and were kept moderately hyperglycemic by daily insulin injections. After 12 months, two subgroups - progressors and nonprogressors - could be formed based on the degree of glomerulosclerosis. Only the progressors exhibited renal TLR4/NF-KB/IL-6 activation. This scenario was already present in rats with short-term DM (two months), at a time when no albuminuria or overt glomerulosclerosis can be detected. Chronic treatment with the NF-kB inhibitor, pyrrolidine dithiocarbamate (PDTC), prevented the renal TLR4/NF-kB/IL-6 activation, while exerting no interference on blood glucose. PDTC abrogated the increase in albuminuria, prevented the development of glomerular injury/inflammation and oxidative stress in DM rats. In addition, the NF-kB p65 component was detected in sclerotic glomeruli and inflamed interstitial areas in biopsy material from patients with type $1 \mathrm{DM}$. These observations indicate that the renal NF-KB pathway plays a key role in the development and progression of experimental DKD, and can become an important therapeutic target in the quest to prevent the progression of human DKD.
\end{abstract}

Descriptors: renal insufficiency, chronic; diabetes mellitus; streptozocin; diabetic nephropathies; immunity, innate; NF-kappa B. 


\section{INTRODUÇÃO}

A doença renal diabética (DRD) é uma complicação frequente da Diabetes Mellitus (DM) e constitui hoje uma das mais importantes causas de doença renal crônica (DRC) - e de necessidade de terapia de reposição renal em todo o mundo (1). De acordo com dados da Sociedade Brasileira de Nefrologia (2016), a DM, juntamente com a hipertensão, é uma das maiores causas de insuficiência renal crônica dialítica no Brasil (2).

Esse papel destacado da DRD pode ser explicado por diversos fatores. A prevalência da própria diabetes, especialmente do tipo 2 , tem aumentado constantemente nos últimos anos, em consequência do envelhecimento da população mundial e do aumento da prevalência de sobrepeso e obesidade. Além disso, os avanços terapêuticos no tratamento das complicações da diabetes têm propiciado maior sobrevida aos diabéticos, o que resulta em um maior tempo para a progressão da nefropatia.

\section{Mecanismos envolvidos na patogênese da DRD}

Os mecanismos que levam ao estabelecimento da DRD são complexos e, apesar do progresso ocorrido nas últimas décadas, ainda estão longe de serem totalmente compreendidos. Os fatores envolvidos na patogênese da doença podem ser categorizados como metabólicos, hemodinâmicos e inflamatórios.

A hiperglicemia é a principal alteração metabólica associada à doença, e já foi amplamente demonstrado que o controle desse parâmetro por si só, através da administração de insulina, é capaz de prevenir alterações 
observadas na DRD $(3,4)$. Além disso, estudos realizados pelo The Diabetes Control and Complications Trial Research Group mostraram que o controle da glicemia previne o desenvolvimento de outras complicações associadas à diabetes, como a retinopatia e a neuropatia $(5,6)$. As vias pelas quais a hiperglicemia leva às alterações estruturais e funcionais observadas na DRD ainda não foram totalmente esclarecidas. No entanto, diversos mecanismos têm sido propostos para explicar esse efeito patogênico da hiperglicemia.

Nakamura e colaboradores (1993) demonstraram que a expressão do fator de crescimento e transformação beta (TGF- $\beta$ ), uma citocina pró-fibrótica, é aumentada em glomérulos de ratos com diabetes induzida por estreptozotocina (STZ) e a administração de insulina controlou a hiperglicemia e reduziu parcialmente essa superexpressão de TGF- $\beta$ (7). Também já foi demonstrado que diferentes tipos celulares cultivados em ambiente hiperglicêmico apresentam aumento na expressão dessa citocina, inclusive células de túbulo proximal (8) e células mesangiais (9).

O aumento nos níveis de glicose resulta em glicosilação não enzimática de proteínas circulantes e estruturais, gerando produtos finais de glicação avançada (AGEs). Nesse processo, o grupo amino da proteína reage com a glicose, formando as bases de Schiff. Essas moléculas sofrem rearranjos em sua conformação, o que resulta na formação dos AGEs $(10,11)$. Os AGEs ligam-se a receptores específicos (RAGEs), o que resulta em aumento na expressão de citocinas e ativação de vias que podem estar envolvidas na patogênese da DRD (12). Além disso, já foi demonstrado que o tratamento de animais diabéticos com anticorpos anti-RAGE resultou em melhora nas alterações renais observadas na DRD (13). Outras vias alternativas que 
envolvem o metabolismo da glicose também podem ser responsáveis pelos efeitos deletérios da hiperglicemia sobre os rins, como a via dos polióis (14). A enzima aldose redutase catalisa a formação de polióis a partir da glicose, e o acúmulo desses produtos osmoticamente ativos nas células promove entrada de água (15). Contudo, as reais consequências desses mecanismos para 0 tecido renal ainda não estão bem estabelecidas.

O aumento no ritmo de filtração glomerular (RFG) e a hipertensão intraglomerular são alterações hemodinâmicas que contribuem significativamente para a progressão da DRD (16). Em 1967, Ditzel e colaboradores observaram um aumento na taxa de filtração glomerular em pacientes jovens com DM de curta duração (17). Esse aumento no RFG também foi observado por Mogensen (1972) em pacientes com diabetes tipo 1 de longo prazo (18). Hostetter e colaboradores (1981) demonstraram que a pressão capilar glomerular $\left(\mathrm{P}_{\mathrm{GC}}\right)$ encontra-se elevada em ratos tornados diabéticos por STZ (19). Zatz e colaboradores (1986) também observaram elevação na $\mathrm{P}_{\mathrm{GC}}$, com aumento progressivo da albuminúria e lesões glomerulares nesse mesmo modelo de diabetes (20). Nesse estudo, 0 tratamento com enalapril, um inibidor da enzima conversora de angiotensina, foi capaz de reduzir significativamente a $P_{G C}$ nos animais diabéticos, normalizando a albuminúria e prevenindo danos glomerulares. Esses achados evidenciaram um papel fundamental da hipertensão glomerular na progressão da DRD.

A DRD apresenta um caráter inflamatório e a inflamação está envolvida tanto na patogênese como na progressão da doença (21-23). Os mecanismos imunes responsáveis por desencadear esse processo ainda não foram 
elucidados, mas existem evidências de que a ativação da imunidade inata pela diabetes tenha um papel relevante para o dano renal (24), podendo afetar podócitos, bem como aos outros tipos celulares presentes nos glomérulos e, possivelmente, as próprias células tubulares, especialmente as proximais.

\section{Imunidade Inata na DRD}

A imunidade inata é uma primeira linha de defesa do organismo contra o dano tecidual causado por patógenos ou mesmo por moléculas endógenas (25). O sistema imune inato conta com uma extensa rede de mecanismos de sinalização, que envolvem o reconhecimento de padrões moleculares por receptores celulares (Figura 1). 


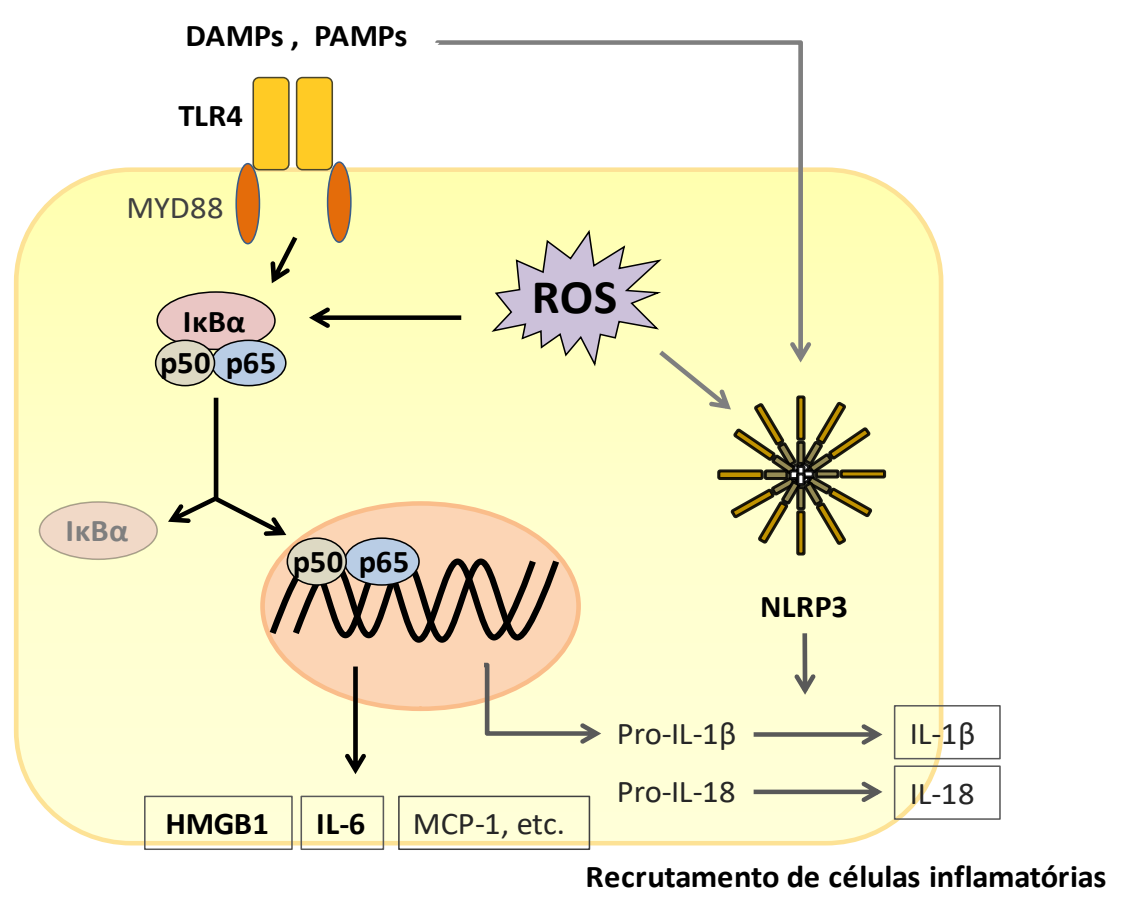

Figura 1. Padrões moleculares de patógenos (PAMPs) e/ou resultantes de dano celular (DAMPs), podem ativar os receptores TLR4, que, através de uma sinalização mediada pela proteína adaptadora MyD88, promovem fosforilação e degradação da proteína inibitória do sistema NF-kB, a $1 \mathrm{kBa}$, permitindo a translocação do heterodímero p50/p65 do citoplasma para o núcleo. Essa ativação do sistema NF-kB, que pode ocorrer também por espécies reativas de oxigênio (ROS), resulta em transcrição de genes envolvidos no processo inflamatório, como, por exemplo, MCP-1, IL-6, HMGB1 e pró-interleucinas -1 $\beta$ e -18. O inflamassoma NLRP3 pode ser ativado pelos próprios DAMPs e PAMPs e/ou por ROS, promovendo a maturação dessas próinterleucinas em IL-1 $\beta$ e IL-18 maduras. Esse ambiente inflamatório leva ao recrutamento de células inflamatórias, como macrófagos e linfócitos.

Os Toll-Like Receptors (TLRs) constituem uma família de receptores celulares localizados em células inflamatórias, como macrófagos e linfócitos, e de revestimento, como células epiteliais e endoteliais, entre outros tipos celulares $(25,26)$. Eles são responsáveis por reconhecer moléculas comuns a um grande número de patógenos (PAMP - pathogen associated molecular pattern), como toxinas e fragmentos de DNA, e também reconhecem estruturas resultantes da destruição/estresse de células do próprio organismo (DAMP damage associated molecular pattern), tais como componentes de matriz 
extracelular e a high mobility group box protein-1 (HMGB1, uma proteína nuclear) $(27,28)$. Os TLRs encontram-se unidos a proteínas de membrana ou intracelulares, como a myeloid differentiation primary response 88 (MyD88), promovendo, quando ocupados, a estimulação de fatores de transcrição e, consequentemente, a produção de uma série de mediadores que aumentam a intensidade da resposta imune. Células sanguíneas são atraídas ao local inflamado e, por sua vez, sintetizam novos mediadores em um processo de realimentação positiva (27). Assim, os TLRs, e a sequência inflamatória que eles desencadeiam, representam uma importante ferramenta da imunidade inata, sendo responsáveis pela proteção dos tecidos contra invasões por microrganismos e por detectar danos a suas próprias células, iniciando uma reação a eles.

Recentemente, foram descobertos outros receptores citosólicos também capazes de reconhecer DAMPs e PAMPs presentes no interior das células. Dentre esses receptores, os que mais se destacam atualmente são os NLRs (Nucleotide-binding Oligomerization Domain (NOD)-Like Receptors), como o NLRP3 (Nucleotide-binding oligomerization domain, Leucine-rich Repeat and Pyrin domain containing-3). Quando ativado, o NLRP3, associado à Apoptosisassociated Speck-like protein containing a Caspase recruitment domain adaptor protein (ASC) e à pró-caspase-1 (25), sofre um processo de oligomerização, formando complexos moleculares conhecidos como inflamassomas. A prócaspase é então convertida a caspase-1, que catalisa a transformação de prómediadores, como as pró-interleucinas $1 \beta$ e 18, em mediadores ativos, que desencadeiam uma sequência de eventos inflamatórios destinados em 
princípio a conter uma possível invasão microbiana e a remover os produtos resultantes da destruição de células (25).

Os TLRs e NLRs não agem de maneira independente, existindo vários pontos de contato entre as sequências de eventos desencadeados por cada um deles (29). O conjunto desses receptores tem a capacidade de reagir de maneira imediata às ameaças, mediante o recrutamento e a ativação de contingentes de células circulantes, bem antes da ativação da resposta imune adaptativa. Contudo, além de atuar como um mecanismo de defesa, distúrbios em sua ativação podem promover ou agravar uma série de doenças, inclusive renais (24).

Estudos recentes têm demonstrado a participação de receptores pertencentes às vias de sinalização da imunidade inata na DRD. A expressão do receptor TLR2 mostrou-se aumentada em um modelo animal de DRD (30). Em outro estudo, realizado por Lin e colaboradores, o receptor TLR4 também apresentou um aumento de expressão em células de túbulo proximal cultivadas em meio rico em glicose e no tecido renal de pacientes com diabetes tipo 2 e de camundongos diabéticos (31). Nesses dois estudos, o aumento de expressão dos receptores TLR2 e TLR4 foi relacionado à maior liberação de citocinas pró-inflamatórias e à infiltração de monócitos no tecido renal. Outro estudo demonstrou que a inibição de TLR4 por um imunomodulador é capaz de prevenir o desenvolvimento de DRD em animais diabéticos e reduzir a síntese de citocinas pró-inflamatórias (32). Também já foi demonstrado um aumento da expressão de proteínas que compõem os inflamassomas NLRP, como NLRP3, ASC e Caspase-1, em tecido renal de ratos com DM de curta duração, sugerindo a participação desse complexo proteico na DRD (33). 


\section{O sistema NF-kB na DRD}

A via de sinalização do fator de transcrição Nuclear Factor-Kappa B (NFKB) é uma importante via da imunidade inata que também pode estar envolvida na patogênese da DRD. O NF-kB foi inicialmente identificado em linfócitos $B$ (34) e está presente em diversos tipos celulares, podendo ser ativado por estímulos patológicos e fisiológicos, como por exemplo, partículas virais, citocinas ou até mesmo estresse mecânico (35-38). Há evidências também de que o sistema NF-kB pode ser ativado pelo estresse oxidativo (39), que é uma perturbação das funções celulares normais, causada pelo desequilíbrio entre a produção de espécies reativas de oxigênio e a capacidade antioxidante natural das células (40). O NF-kB é um heterodímero formado principalmente pelas subunidades p50 e p65, ligadas a uma subunidade inibidora, a IkBa. O sistema encontra-se inativo no citoplasma das células e, quando ativado, ocorre a fosforilação e degradação da proteína inibitória $\mid k B a$, permitindo que 0 heterodímero p50/p65 migre para o núcleo, entre em contato com o DNA e promova a transcrição de genes que codificam moléculas inflamatórias (41), como a proteína de quimiotaxia para monócitos-1 (MCP-1), a interleucina-6 (IL6), o fator de necrose tumoral- $\alpha$ (TNF- $\alpha$ ), o HMGB1 e as pró-interleucinas-1 $\beta$ e 18 (42, 43). O sistema NF-kB é uma das vias de sinalização envolvidas em uma variedade de doenças inflamatórias (42), inclusive em doenças renais proteinúricas $(44,45)$, sugerindo a possibilidade de que esse sistema participe da patogênese da DRD.

A ativação do sistema NF-kB pode ser bloqueada ao impedir a fosforilação e, portanto, a degradação do IkBa (41). O composto ditiocarbamato de pirrolidina (PDTC) é um potente inibidor do sistema NF-kB, já que impede a 
fosforilação e degradação da IKBa e, somada a esse efeito, a droga ainda apresenta uma ação antioxidante $(35,46)$. Em um estudo publicado por nosso laboratório, a administração de PDTC foi capaz de prevenir parte das alterações renais associadas ao modelo de ablação renal de 5/6 (Nx), atenuando a glomeruloesclerose e a fibrose intersticial (47). Essa renoproteção também foi observada no modelo de DRC por sobrecarga de adenina, no qual o tratamento com PDTC atenuou significativamente a fibrose e a inflamação intersticial (48). Evidências de um efeito renoprotetor da inibição do NF-KB em modelos experimentais de diabetes de curto prazo também estão emergindo (49). Esse conjunto de observações sugere que a inibição do sistema NF-kB exerce um efeito renoprotetor na DRD. No entanto, os dados publicados que abordam o papel do NF-kB - e o efeito de sua inibição - na progressão do DRD experimental em longo prazo são escassos ou inexistentes.

Diante dessas evidências, nós formulamos a hipótese de que o sistema NF-KB está envolvido na patogênese e na progressão da lesão renal em um modelo muito bem estabelecido de DM tipo 1 induzido por STZ, com hiperglicemia mantida em níveis moderados por injeções diárias de insulina $(20,23,50,51)$. Procuramos também verificar se essa ativação ocorre na DM humana, examinando material de biópsia de pacientes diabéticos. 


\section{OBJETIVOS}

- Testar a hipótese de que a ativação do sistema NF-KB encontra-se aumentada nos rins de animais diabéticos por STZ que desenvolvem nefropatia em longo prazo.

- Verificar se essa via é ativada precocemente.

- Verificar o efeito do tratamento com PDTC, um inibidor do NF-kB, sobre o desenvolvimento da DRD nesse modelo.

- Avaliar a presença do NF-KB em biópsias renais de pacientes com DRD. 


\section{MÉTODOS}

Foram utilizados ratos Munich-Wistar obtidos de uma colônia dessa linhagem de ratos estabelecida no biotério do Laboratório de Fisiopatologia Renal. Os animais foram mantidos em temperatura ambiente de $22 \pm 1{ }^{\circ} \mathrm{C}$, umidade relativa de $60 \pm 5 \%$ e ciclo claro/escuro de $12 / 12 \mathrm{~h}$. Durante o estudo, todos os ratos foram mantidos com ração comercial (Nuvilab, Curitiba, Brasil), acrescida de $15 \%$ de caseína. Os procedimentos experimentais utilizados neste estudo seguiram as normas da Comissão de Ética do Hospital das Clínicas da Faculdade de Medicina da Universidade de São Paulo (CAPPesq). Este projeto foi registrado na Comissão de Ética no Uso de Animais da Universidade de São Paulo (Protocolo de Pesquisa nº 034/15).

\subsection{OBTENÇÃO DO MODELO EXPERIMENTAL}

A DM foi induzida pela injeção de STZ (Sigma-Aldrich, St. Louis, EUA), 65 $\mathrm{mg} / \mathrm{kg}$ em tampão citrato ao $\mathrm{pH}$ de 4,2, através de uma veia caudal, em ratos previamente anestesiados com Ketamina (50 mg/kg, i.m.) e Rompun (10 $\mathrm{mg} / \mathrm{kg}$, i.m.). A glicemia foi medida em pequenas amostras de sangue obtidas da cauda. Os ratos que de início não desenvolveram hiperglicemia foram descartados. A glicemia foi mantida entre 350 e $450 \mathrm{mg} / \mathrm{dL}$ por meio de injeções subcutâneas diárias de insulina NPH (1 a 4 unidades/rato). Apenas tampão citrato foi injetado nos animais utilizados como controles (CN).

Ratos diabéticos (grupo DM, $\mathrm{n}=32$ ) e controles não diabéticos (grupo $\mathrm{CN}=29)$ foram acompanhados por 12 meses após a injeção de STZ. Após os 
12 meses de estudo, dois subgrupos de ratos DM foram formados: DRD-, constituído pelos 10 ratos diabéticos com menor porcentagem de glomérulos escleróticos (\%EG); DRD +, contendo os 10 ratos diabéticos com maior \%EG. Doze ratos $\mathrm{CN}$ foram utilizados para a comparação com esses grupos. Uma coorte adicional de 7 animais DM e $5 \mathrm{CN}$ foi acompanhada por 2 meses após a injeção de STZ.

Em uma coorte separada de animais, 11 ratos DM foram tratados com o inibidor do NF-KB, PDTC (Sigma-Aldrich, St. Louis, EUA), dissolvido na água a $60 \mathrm{mg} / \mathrm{Kg} / \mathrm{dia}$, e receberam injeções diárias de insulina (como descrito anteriormente), por 12 meses (Grupo DM+PDTC). Dezesseis animais DM recebendo apenas veículo e injeções diárias de insulina (grupo DM+V). Os doze ratos $\mathrm{CN}$ foram utilizados para comparação.

\subsection{GRUPOS EXPERIMENTAIS (RESUMO)}

Grupo CN: ratos não diabéticos, sem nenhum tratamento, observados até 12 meses após a indução dos animais diabéticos;

Grupo DM: ratos diabéticos por STZ, tratados apenas com insulina e observados até 12 meses após a indução de DM.

DRD-: Os 10 ratos diabéticos, tratados apenas com insulina e acompanhados por 12 meses, com os menores valores de \%EG;

DRD+: Os 10 ratos diabéticos, tratados apenas com insulina e acompanhados por 12 meses, com os maiores valores de \%EG. 
Grupo $\mathrm{DM}+\mathrm{V}$ : ratos diabéticos por STZ, tratados apenas com insulina e veículo, observados até 12 meses após a indução de DM;

Grupo DM+PDTC: ratos diabéticos por STZ, tratados com insulina e PDTC (60 $\mathrm{mg} / \mathrm{kg} / \mathrm{dia}$ ) na água de beber, observados até 12 meses após a indução de DM.

Grupo $\mathbf{C N}_{2 m}$ : Ratos não diabéticos, sem nenhum tratamento, observados até 2 meses após a indução dos animais diabéticos;

Grupo $\mathbf{D M}_{2 \mathrm{~m}}$ : ratos diabéticos por $\mathrm{STZ}$, tratados apenas com insulina e observados até 2 meses de DM.

\subsection{PROCEDIMENTOS GERAIS}

Para os grupos acompanhados por 12 meses, o peso corpóreo e a relação albumina urinária/creatinina urinária (Ualb/Ucr) foram determinados trimestralmente. Os animais acompanhados por 2 meses tiveram esses parâmetros avaliados ao final desse período. Ao término do período de acompanhamento (2 ou 12 meses), os animais foram então anestesiados com ketamina (50 mg/kg, i.m.) e xilazina (10 mg/kg, i.m.). O rim direito foi perfundido retrogradamente in situ através da aorta abdominal apenas com solução salina, cortado e rapidamente congelado a $-80{ }^{\circ} \mathrm{C}$ para avaliação de proteínas no tecido total ou na fração nuclear. O rim esquerdo foi perfundido in situ com soro fisiológico para remoção de sangue dos vasos renais e após, com solução

Dubosq-Brasil para fixação do tecido. O tecido renal foi pesado e então desidratado, diafanizado e impregnado com parafina através de um processador automático de tecidos (Jung Histokinette 2000, Leica Instruments 
$\mathrm{GmbH}$, Nussloch, Alemanha). Em seguida, o tecido renal foi incluído em blocos de parafina, cortado em seções de $4 \mu \mathrm{m}$ por meio de um micrótomo especial e montado em lâminas secas para análise histológica e em lâminas silanizadas (3-Aminopropil-trietoxi-silano, Sigma, St. Louis, EUA) para imuno-histoquímica.

\subsection{ANÁLISES BIOQUÍMICAS}

Glicemia: Os níveis glicêmicos foram avaliados por reflectometria (Advantage, Roche Diagnostics, Indianápolis, EUA) em amostras colhidas de uma veia caudal.

Albuminúria: A concentração de albumina na urina foi medida por imunodifusão radial, empregando um anticorpo específico anti-albumina de rato (MP Biomedicals LLC, Santa Ana, EUA) (52).

Concentração de creatinina: A concentração urinária de creatinina foi determinada por análise colorimétrica, utilizando kit comercial disponível (Labtest Diagnóstica, Lagoa Santa, Brasil).

\subsection{ANÁLISES HISTOLÓGICAS}

A coloração pelo Ácido Periódico de Schiff (PAS) foi utilizada para a avaliação da esclerose glomerular. A quantificação da \%EG foi realizada através da contagem do número de glomérulos com esclerose, independente da extensão da lesão. Para essa avaliação foram analisados 200 glomérulos por lâmina, sob aumento de 400x (53). 


\subsection{ANÁLISES IMUNO-HISTOQUÍMICAS}

A infiltração por macrófagos e a expressão renal de zonula occludens-1 (ZO-1), p65 e NLRP3 foram avaliadas por meio de reação imuno-histoquímica.

Os tecidos (previamente parafinizados e montados em lâminas silanizadas) foram colocados em estufa a $60^{\circ} \mathrm{C}$ por 30 minutos, submetidos à desparafinização em 3 banhos de xilol e reidratados em etanol (concentrações decrescentes) e água destilada. A recuperação antigênica foi realizada em panela a vapor por 30 minutos, à temperatura de $98{ }^{\circ} \mathrm{C}$, em solução de ácido cítrico $10 \mathrm{mM}$ de $\mathrm{pH}$ 6,0. Para evitar o ressecamento dos cortes, todas as incubações foram realizadas em câmara úmida.

A identificação das células positivas para macrófagos foi realizada pelo método de APAAP (Fosfatase Alcalina Anti-Fosfatase Alcalina). Após a desparafinização e recuperação antigênica, os tecidos foram submetidos ao bloqueio de marcação inespecífica com soro não imune de coelho (Dako, Carpinteria, EUA), em concentração 1:20 por 30 minutos. Os tecidos foram incubados com o anticorpo primário desenvolvido em camundongo anti-ED-1 (Serotec, Oxford, Reino Unido) na diluição $1: 200$, à temperatura de $3-8^{\circ} \mathrm{C}$ durante um período de 18 horas. Após a retirada do excesso de anticorpo primário, os cortes foram lavados com TBS e incubados com o anticorpo secundário anti-camundongo desenvolvido em coelho (Dako, Carpinteria, CA, EUA), na diluição 1:50, à temperatura ambiente, durante 30 minutos. Após nova lavagem em TBS, os cortes foram incubados com o Complexo APAAP por 30 minutos. Ao final desses procedimentos, os tecidos foram revelados em tempo variável com substrato cromogênico Permanent-Red. As células 
positivas para ED-1 foram visualizadas graças à precipitação do produto da reação da fosfatase alcalina do Complexo APAAP com o Permanent-Red presente no substrato cromogênico. A contracoloração foi realizada com hematoxilina de Mayer durante 1 minuto. Os cortes foram colocados entre a lâmina e a lamínula com meio de montagem aquoso de Mayer (Glycergel), e devidamente etiquetados. A quantificação de macrófagos infiltrados foi realizada através da contagem de células marcadas no córtex renal em aumento de 400x. Foram examinados 30 campos para cada seção, correspondendo a uma área de $0,08 \mathrm{~mm}^{2}$. Os resultados foram apresentados em células $/ \mathrm{mm}^{2}$.

A identificação do NLRP3 foi realizada utilizando o método de Imunoperoxidase Indireta. Após a desparafinização e recuperação antigênica, foi feito o bloqueio da peroxidase endógena com solução de peróxido de hidrogênio a $30 \%$ por 30 minutos. As lâminas foram submetidas ao bloqueio de marcação inespecífica utilizando solução Protein Block® (Dako, Carpinteria, EUA) e, em seguida, receberam o anticorpo primário anti-NLRP3 desenvolvido em coelho (Novus Biologicals, Littleton, EUA). Após 18 horas de incubação, os tecidos foram incubados com polímero-HRP conjugado com anticorpo secundário (Dako, Carpinteria, EUA). A revelação foi realizada com o cromógeno DAB (Dako, Carpinteria, EUA).

A integridade podocitária e de suas conexões foi avaliada através da análise da expressão do antígeno ZO-1, através do método de Imunoperoxidase Indireta. Após a desparafinização e recuperação antigênica, foi feito o bloqueio da peroxidase endógena com solução de peróxido de hidrogênio a $30 \%$ por 30 minutos. As lâminas foram submetidas ao bloqueio de 
marcação inespecífica utilizando soro não imune de cavalo (Vector Lab, Burlingame, EUA) diluído em uma solução de leite desnatado a $2 \%$ e, em seguida, com anticorpo primário anti-ZO-1 desenvolvido em coelho (Zymed Laboratories, South San Francisco, EUA). Após 18 horas de incubação, os tecidos foram incubados com polímero-HRP conjugado com anticorpo secundário (Dako, Carpinteria, EUA). A revelação foi realizada com o cromógeno DAB (Dako, Carpinteria, EUA).

Para a avaliação da porcentagem da área glomerular ocupada por NLRP3 ou por ZO-1, utilizamos um método de contagem de pontos. Foram avaliados 30 campos microscópicos consecutivos, sob aumento final de 400x, utilizando uma matriz de 144 pontos.

A marcação do p65, um dos principais componentes do sistema NF-KB, utilizou o método de Imunoperoxidase Indireta. Após a desparafinização do tecido e recuperação antigênica, foi feito o bloqueio da biotina endógena através da incubação com solução de bloqueio de Avidina e Biotina (Dako, Carpinteria, EUA) por 15 minutos cada. Depois foi feito o bloqueio da marcação inespecífica com soro não imune de cavalo (Vector Lab, Burlingame, EUA) diluído a 1:50 em solução de BSA a 5\%, durante 45 minutos. Os tecidos foram incubados com o anticorpo primário anti-p65 desenvolvido em coelho (Cell Signaling, Danvers, EUA) diluído a 1:10000, à temperatura de $3-8^{\circ} \mathrm{C}$, durante um período de 18 horas. Após a retirada do excesso de anticorpo primário, os cortes foram lavados com TBS e incubados a 1:3000 com o anticorpo secundário anti-coelho biotinilado (Vector Lab, Burlingame, EUA), à temperatura ambiente, durante 45 minutos. Após nova lavagem em TBS, os cortes foram incubados com o sistema ABC Avidina/Biotina (Vector Lab, 
Burlingame, EUA) por 30 minutos. Ao final desses procedimentos, os tecidos foram revelados em tempo variável com substrato cromogênico DAB (Dako, Carpinteria, EUA).

\subsection{ESTUDO COM MATERIAL DE BIÓPSIA}

O tecido renal humano foi obtido de material de biópsia incluído em parafina, arquivado na Divisão de Patologia do Hospital das Clínicas da FMUSP. Foram analisados cinco cortes, obtidos de pacientes com diabetes tipo 1 com quadro de proteinúria maciça, que havia levado à suspeita clínica de uma glomerulopatia primária associada, mas que receberam diagnóstico de DRD isolada após cuidadosa análise por patologista qualificado. $O$ tecido renal normal foi obtido de um paciente falecido por trauma. A deteç̧ão do componente p65 utilizou as técnicas imuno-histoquímicas descritas anteriormente. O uso de material humano foi aprovado pela Comissão de Ética para Análise de Projetos de Pesquisa do Hospital das Clínicas da FMUSP (Processo n $\left.{ }^{\circ} 45163715.4 .0000 .0068\right)$.

\subsection{ANÁLISES POR WESTERN BLOT}

Para a detecção do conteúdo proteico de TLR4, IL-6, HMGB1, Heme oxigenase-1 (HO-1) e Superóxido dismutase 2 (SOD2) por Western blot no tecido renal total, amostras de rim pesando entre 100 e $200 \mathrm{mg}$ foram colocadas em tubos de polipropileno reforçado, contendo microesferas de cerâmica, juntamente com tampão RIPA (Thermo Fisher Scientific, 
Massachusetts, EUA) e inibidores de proteases e fosfatases (Complete-EDTA e PhosSTOP, Roche, Mannheim, Alemanha), para serem homogeneizados no aparelho OMNI BEAD RUPTOR 24 (Omni International, Kennesaw, EUA). O teor proteico foi determinado utilizando um kit comercial (Pierce BCA Protein Assay Kit, Thermo Fisher Scientific, Massachusetts, EUA), seguindo as instruções do fabricante. Para a corrida eletroforética, foram utilizados $100 \mu \mathrm{g}$ de proteína do extrato tecidual diluído em tampão de amostra (Laemmli Sample Buffer, Bio-Rad Lab, Hercules, EUA).

A corrida das amostras para análise de TLR4 foi realizada em gel de poliacrilamida 10\% (SDS-PAGE) e se completou em aproximadamente 1 hora e 30 minutos, a 120 Volts. Em seguida o gel foi transferido (transferência úmida) para uma membrana de nitrocelulose, durante 2 horas, a $400 \mathrm{~mA}$. Para a confirmação da transferência, a membrana foi corada com Solução de Ponceau (Sigma-Aldrich, St. Louis, EUA). Posteriormente, a membrana foi lavada com tampão TBSt e o bloqueio de marcação inespecífica foi realizado com BSA a 5\% diluída em tampão TBS, por 2 horas em temperatura ambiente, sob leve agitação. Após o bloqueio, foi realizada a incubação da membrana com o anticorpo primário anti-TLR4 (Santa Cruz Biotechnology, Dallas, EUA), diluído em BSA a 1\%, na proporção 1:250, por 18 horas, à temperatura de $4^{\circ} \mathrm{C}$. Em seguida, a membrana foi lavada com solução de TBSt e incubada com o anticorpo secundário (Anti-rabbit-HRP, Sigma-Aldrich, St. Louis, EUA), na proporção 1:5000, por 2 horas e sob agitação, seguindo-se de nova lavagem com TBSt e revelação.

A corrida das amostras para análise de IL-6, HMGB1, HO-1 e SOD2 foi realizada em gel de poliacrilamida (12 ou 15\%) e se completou em 
aproximadamente 1 hora e 30 minutos, a 120 Volts. Em seguida, os géis foram transferidos (transferência semi-úmida) para membranas de nitrocelulose, durante 45 minutos, a 20 Volts. Posteriormente, foi feita a confirmação da transferência, a lavagem das membranas e o bloqueio da marcação inespecífica. Após o bloqueio, foi realizada a incubação das membranas com os anticorpos primários: anti-IL-6 (Abcam, Cambridge, Reino Unido) diluído em BSA a 1\%, na proporção 1:1000; anti-HMGB1 (Abcam, Cambridge, Reino Unido) diluído em BSA a 1\%, na proporção 1:10000; anti-HO-1 (Abcam, Cambridge, Reino Unido) e anti-SOD2 (Cayman, Ann Arbor, EUA) diluídos em TBSt, nas proporções 1:500 e 1:10000, respectivamente, por 18 horas, à temperatura de $4^{\circ} \mathrm{C}$. Em seguida, a membrana foi lavada com solução de TBSt e incubada com o anticorpo secundário (Sigma-Aldrich, St. Louis, EUA) por 2 horas, sob agitação, seguindo-se nova lavagem com TBSt e revelação.

Para a detecção do conteúdo proteico nuclear de p65 fosforilado (componente do NF-KB ativado) por WB, foi realizada primeiramente a separação da fração nuclear e citoplasmática das células do tecido renal. Para tanto, fragmentos de $100 \mathrm{mg}$ de tecido foram homogeneizados em $1 \mathrm{~mL}$ de solução de lise (20mM HEPES pH7,4, $10 \mathrm{mM} \mathrm{KCl,} 1,5 \mathrm{mM} \mathrm{MgCl} 2,0,25 \mathrm{M}$ Sacarose, 10\% Glicerol, 0,5\% NP-40), com inibidor de fosfatase e inibidor de protease (Complete-EDTA e PhosSTOP, Mannheim, Alemanha). O homogenato foi centrifugado ( 10 minutos, $4^{\circ} \mathrm{C}, 1000 \mathrm{G}$ ) e o sobrenadante (fração citoplasmática) foi descartado. O pellet (fração nuclear) foi lavado 2 vezes mediante suspensão em $1 \mathrm{~mL}$ de solução de lise e posterior centrifugação (10 minutos, $4^{\circ} \mathrm{C}, 1000 \mathrm{G}$ ), com descarte do sobrenadante. Após as lavagens, o pellet foi homogeneizado em $200 \mu \mathrm{L}$ de tampão de amostra 
$(0,125 \mathrm{M}$ Tris- $\mathrm{HCl} \mathrm{pH} 6,8,10 \% 2 \beta$-Mercaptoetanol, 4\% SDS, 10\% Sacarose, 0,2\% Bromophenol-blue), e subsequente centrifugação (10 minutos, $4^{\circ} \mathrm{C}$, 1500G). O pellet foi descartado e o sobrenadante (fração nuclear) armazenado a $-80^{\circ} \mathrm{C}$. Para a corrida eletroforética, foram utilizados $30 \mu \mathrm{L}$ do extrato tecidual, diluídos em tampão de amostra. A corrida foi realizada em gel de poliacrilamida $12 \%$ a 120 Volts e se completou em aproximadamente 1 hora e 30 minutos. Em seguida, o gel foi transferido (transferência semi-úmida) para uma membrana de nitrocelulose, durante 45 minutos a 20 Volts, e foi feita a confirmação de transferência. Após lavagem e bloqueio da marcação inespecífica, foi realizada a incubação da membrana com o anticorpo primário anti-p65 fosforilada (Cell Signaling, Danvers, USA), diluído em BSA 1\%, na proporção 1:100, por 18 horas, à temperatura de $4^{\circ} \mathrm{C}$. Em seguida, a membrana foi lavada com solução de TBSt e incubada com o anticorpo secundário (Anti-rabbit-HRP, Sigma-Aldrich, St. Louis, EUA), por 2 horas e sob agitação, seguindo-se nova lavagem com TBSt e revelação.

A revelação das membranas foi feita por quimioluminescência, utilizando kit comercial (Pierce SuperSignal West Pico Chemiluminescent Substrate, Thermo Fisher Scientific, Massachusetts, EUA), e as imagens foram registradas com aparelho fotodocumentador (UVITEC, Cambridge, Reino Unido). A identificação, a analise e a quantificação das bandas utilizaram o software Uvisoft-UvibandMax (UVITEC, Cambridge, Reino Unido). A proteína constitutiva $\beta$-actina (anti- $\beta$-actina, Sigma-Aldrich, St. Louis, EUA; 1:5000 em BSA 1\%) foi utilizada para a normalização dos resultados das proteínas alvo TLR4, IL-6, HMGB1, HO-1 e SOD2. No caso da p65 fosforilada, foi utilizada a 
proteína constitutiva nuclear histona H2B (anti-histona H2B, Abcam, Cambridge, Reino Unido; 1:1000 em BSA 1\%).

\subsection{ANÁLISE ESTATÍSTICA}

Os resultados foram apresentados como média \pm erro padrão e analisados através de comparação entre grupos, aplicando-se análise de variância (ANOVA) de um fator, com pós-testes de acordo com o método de Newman-Keuls (54), ou aplicando o teste t de Student não pareado quando as comparações envolveram dois grupos, sendo considerados significativos os valores de $p$ inferiores a 0,05 . Os cálculos foram efetuados com o auxílio do software GraphPad Prism® versão 4.0 (GraphPad Software, La Jolla, EUA). 


\section{RESULTADOS}

\section{Após 12 meses, o sistema NF-kB renal foi ativado apenas nos ratos que desenvolveram lesões glomerulares}

Trinta e dois ratos foram tornados diabéticos por STZ e mantidos moderadamente hiperglicêmicos por 12 meses (Figura 2A). Como demonstrado em outros estudos $(20,51)$, os ratos diabéticos apresentaram um aumento progressivo da albuminúria (Figura 2B) e, após 12 meses, um aumento significativo na média de \%EG (Figura 2C).

A

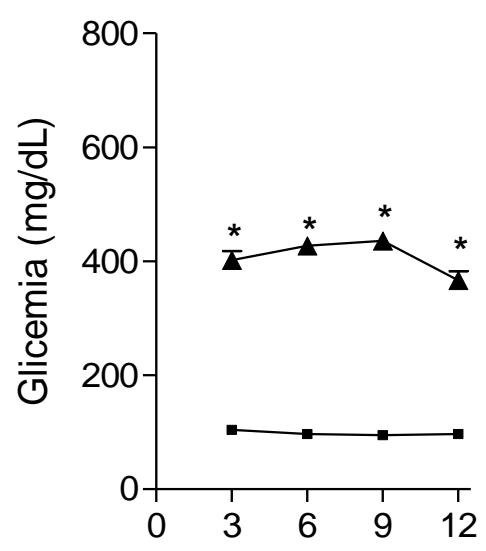

B

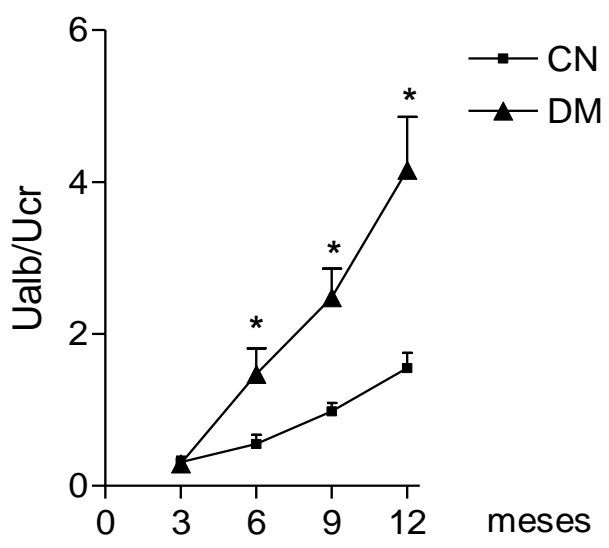

C

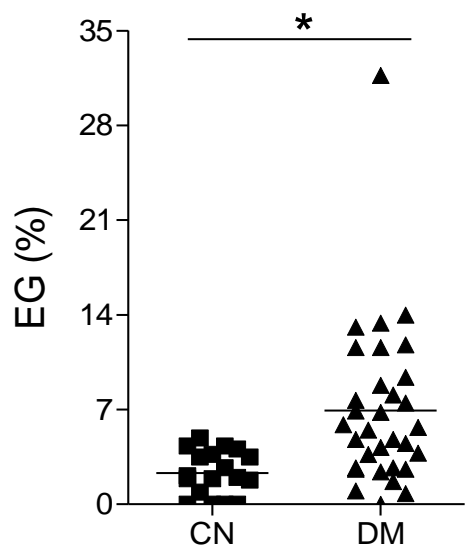

Figura 2. Evolução temporal da (A) concentração de glicose no sangue (Glicemia, mg/dL) e (B) relação creatinina/albumina urinária (Ualb/Ucr) em ratos diabéticos (DM, $n=32)$ e controles (CN, $\mathrm{n}=29$ ). O painel $\mathbf{C}$ mostra a frequência de glomérulos com lesões escleróticas ( $E G, \%)$ em $C N$ e $\mathrm{DM}$ aos 12 meses. Resultados expressos como média $\pm \mathrm{EP} .{ }^{*} \mathrm{p}<0,05 \mathrm{vs}$. CN.

Observamos que cerca de $40 \%$ dos ratos diabéticos exibiam lesões glomerulares evidentes após 12 meses de acompanhamento, enquanto nos demais a frequência de glomérulos com lesões esclerosantes foi semelhante à 
dos ratos controles não diabéticos. Para investigar possíveis diferenças entre essas duas subpopulações de animais diabéticos, foram constituídos dois subgrupos, de acordo com a \%EG: DRD-, composto pelos ratos que tiveram os 10 valores mais baixos de \%EG; e DRD+, constituído por aqueles com os 10 maiores valores de \%EG. Os níveis de glicose no sangue foram similarmente elevados em ambos os subgrupos diabéticos ao longo do estudo (Figura 3A). Como esperado, houve no subgrupo $\mathrm{DRD}+$ um aumento progressivo da albuminúria (Figura 3B) e, aos 12 meses, uma elevada porcentagem de esclerose glomerular (Figura 4A e 4C), com intensa infiltração de macrófagos nos glomérulos (Figura 4B-C).

A

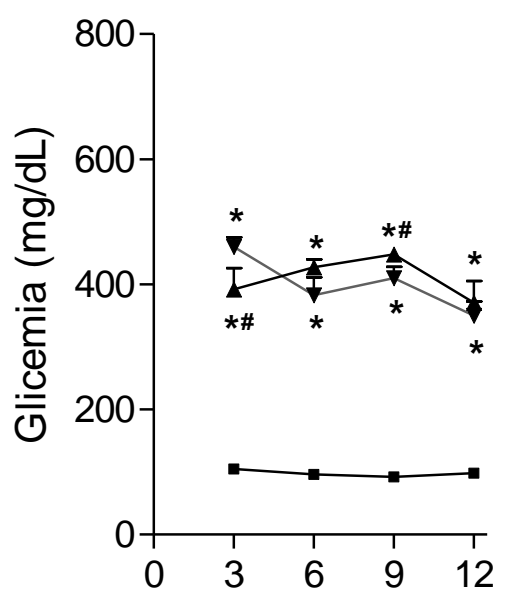

B

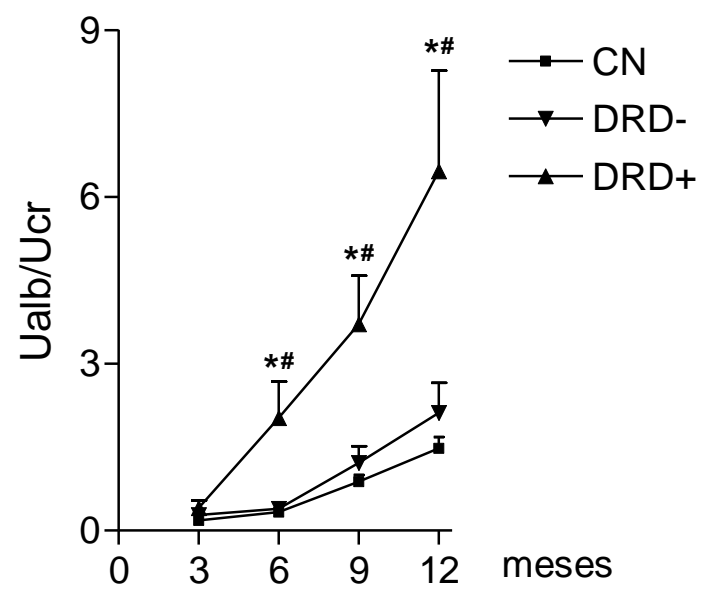

Figura 3. Doze meses após a injeção de STZ, os 10 ratos DM com as maiores percentagens de glomeruloesclerose (\%EG) foram utilizados para criar o subgrupo $\mathrm{DRD}+$, enquanto os 10 ratos $\mathrm{DM}$ com os menores valores de \%EG constituíram o subgrupo DRD-. Foram utilizados 12 ratos não diabéticos, pareados por idade, como controles (CN). A evolução temporal da concentração de glicose no sangue (Glicemia, $\mathrm{mg} / \mathrm{dL}$ ) e a da relação albumina/creatinina urinária (Ualb/Ucr) são mostradas em $\mathbf{A}$ e B, respectivamente. Resultados expressos como média \pm EP. ${ }^{*} p<0.05$ vs. $C N,{ }^{\#} p<0.05$ vs. DRD-. 
A

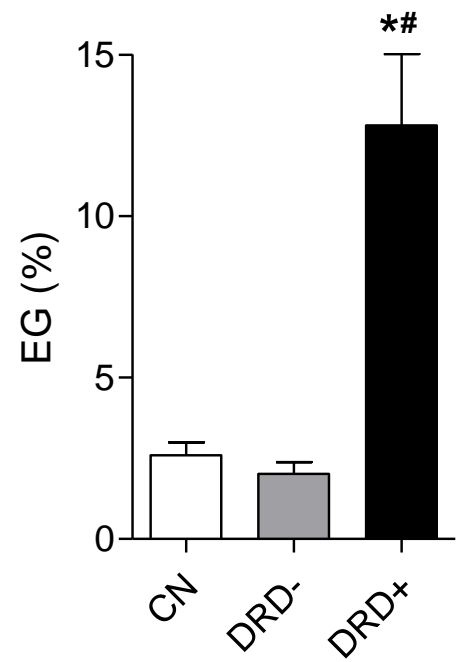

B

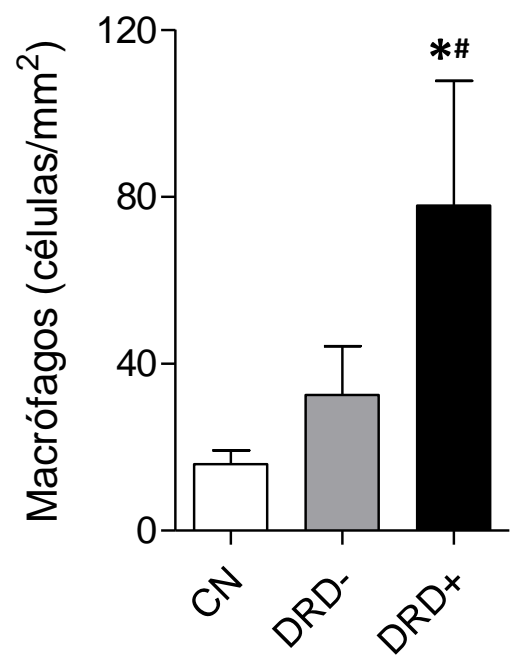

C

$\mathrm{CN}$

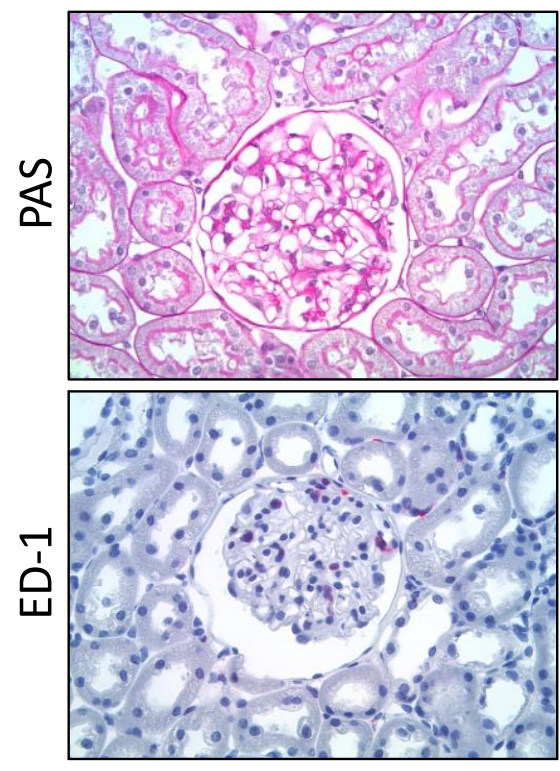

DRD-

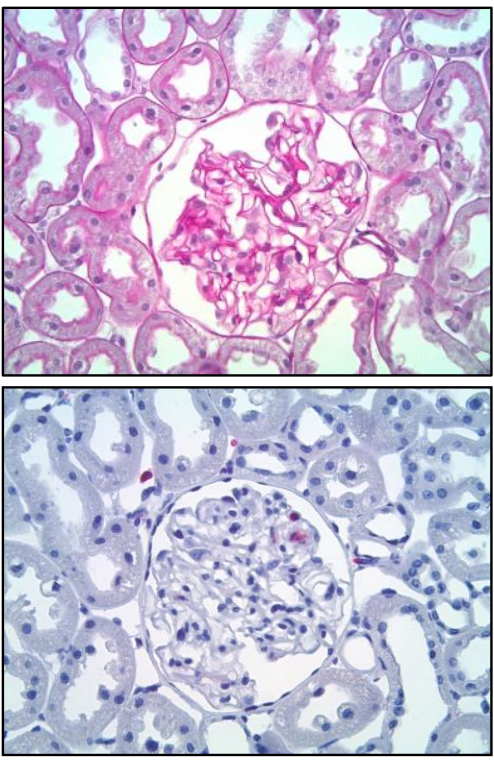

DRD+

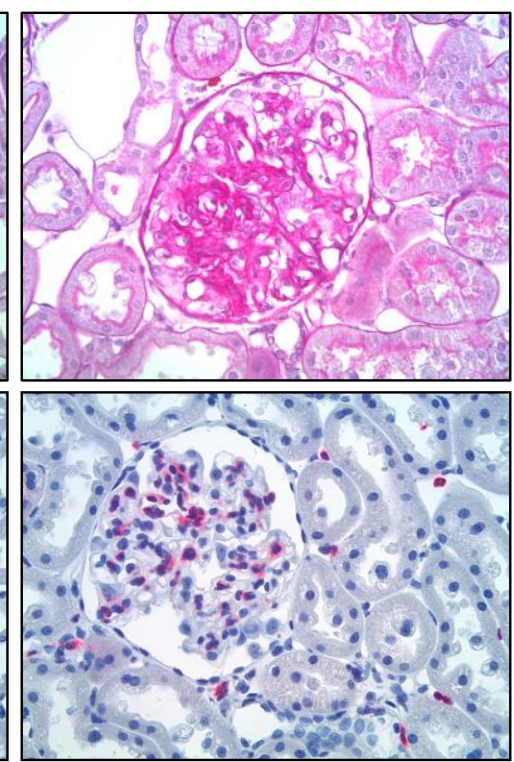

Figura 4. A porcentagem de glomérulos escleróticos (\%EG) e a densidade de macrófagos nos glomérulos (ED-1, células $/ \mathrm{mm}^{2}$ ) dos grupos CN, DRD- e DRD+ aos 12 meses de DM são mostradas nos painéis A e $\mathbf{B}$, respectivamente. Microfotografias representativas do tecido renal corado com PAS (para \%EG) ou imuno-histoquímica (para o antígeno ED-1) são mostradas no painel C (x400). Resultados expressos como média \pm EP. ${ }^{*} p<0,05$ vs. CN, ${ }^{*} p<0,05$ vs. DRD-.

As alterações renais no subgrupo DKD+ foram associadas a um aumento do conteúdo de TLR4, de p65 fosforilada nuclear e IL-6 no tecido renal, enquanto a marcação glomerular para NLRP3 não foi alterada nesse 
grupo (Figura 5A-D e 6). Tal ativação do eixo TLR4/NF-kB/LL-6, bem como alterações na marcação para NLRP3, não foram observadas no subgrupo DRD- (Figura 5A-D e 6). Por imuno-histoquímica, observamos que, nos ratos DRD+, a proteína p65 está presente nos glomérulos e, em um menor grau, na área intersticial (Figura 5E). 
A

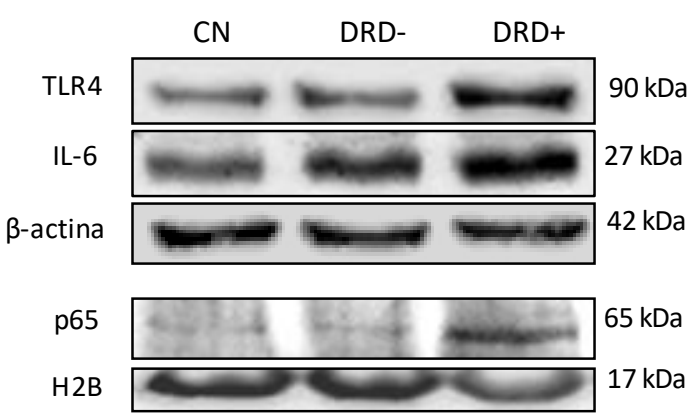

C

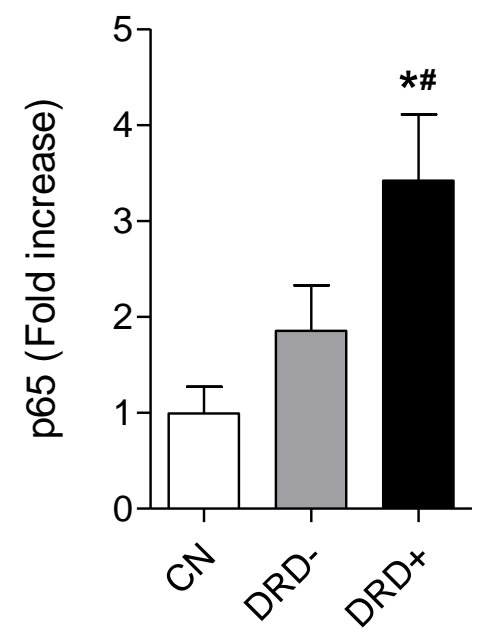

B

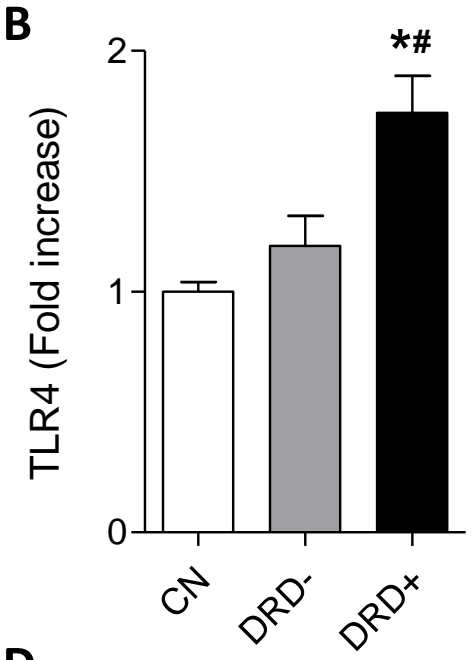

D

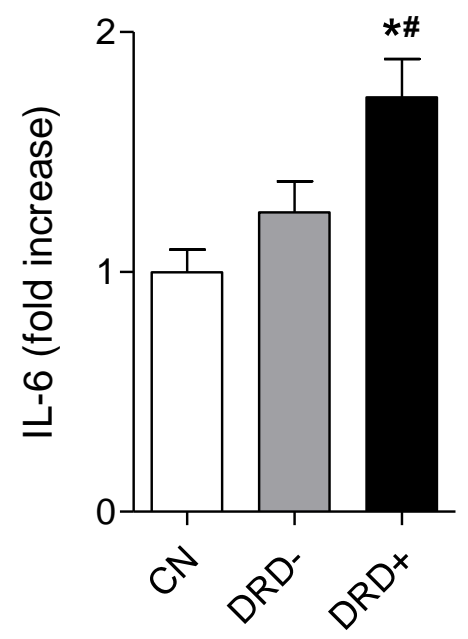

E
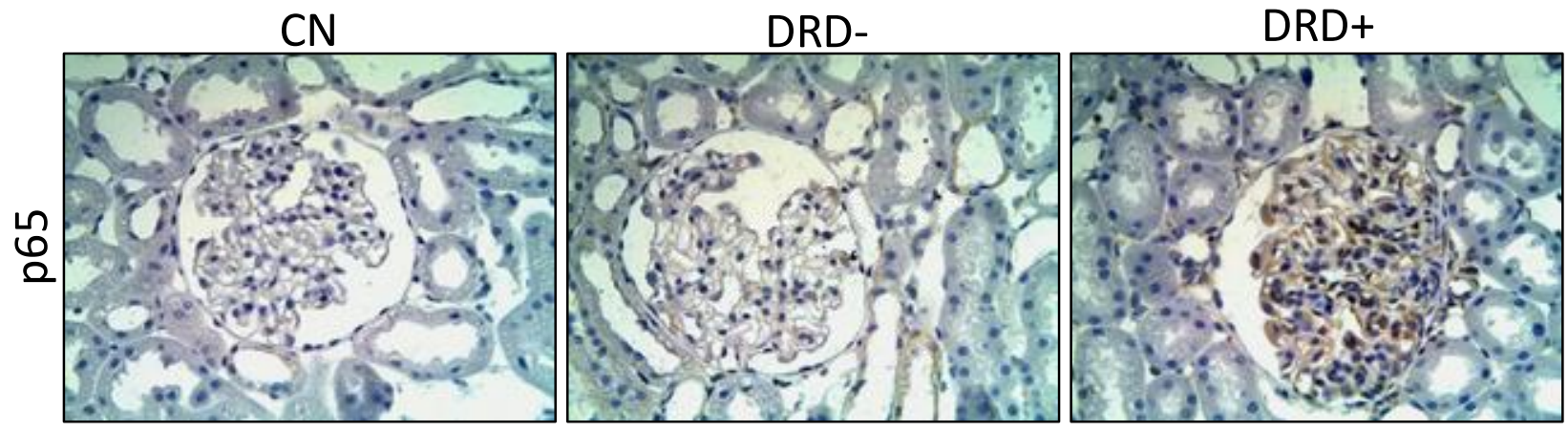

Figura 5. Utilizando Western blot (A), quantificamos o conteúdo renal de toll-like receptor 4 (TLR4, B), fração nuclear do componente fosforilado do NF-kB (p65, C) e interleucina 6 (IL-6, D) dos grupos CN, DRD- e DRD+ aos 12 meses de DM. Microfotografias representativas (E) mostram a presença de imunomarcação positiva para p65 (marrom) nos glomérulos (400x). Resultados expressos como média \pm EP. * $p<0,05$ vs. CN, ${ }^{*} p<0,05$ vs. DRD-. 

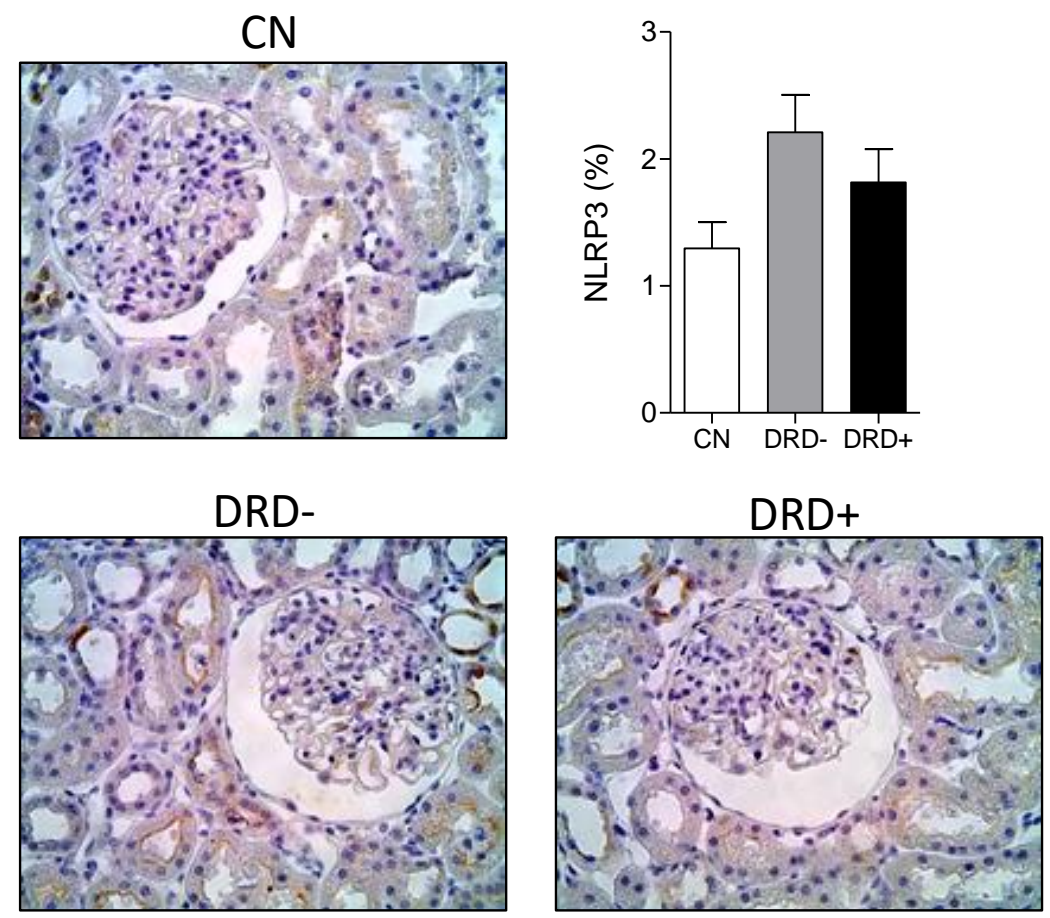

Figura 6. Microfotografias $(400 x)$ representativas da presença nos glomérulos de NLRP3 (marrom) e quantificação da porcentagem de área glomerular positiva para NLRP3 (\%) dos grupos CN, DRD- e DRD+ aos 12 meses de DM. Nenhuma diferença significativa foi detectada entre os grupos. Resultados expressos como média \pm EP.

\section{A ativação do NF-kB precede o desenvolvimento de esclerose glomerular na DM experimental}

Ratos diabéticos por STZ foram mantidos moderadamente hiperglicêmicos por dois meses (Figura 7A). Mesmo com albuminúria ou glomeruloesclerose ainda ausentes (Figura 7B-C), os ratos diabéticos exibiram conteúdo renal aumentado de TLR4 (Figura 8A e 8D) e maior translocação da subunidade p65 para a fração nuclear das células renais (Figura 8B e 8D), além de marcação positiva para p65 na área glomerular (Figura 8E). Consistentemente, a abundância de IL-6 no tecido renal mostrou-se aumentada (Figura 8C-D). 
A

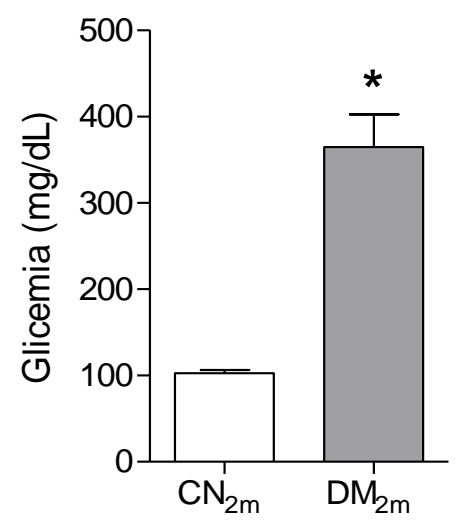

B

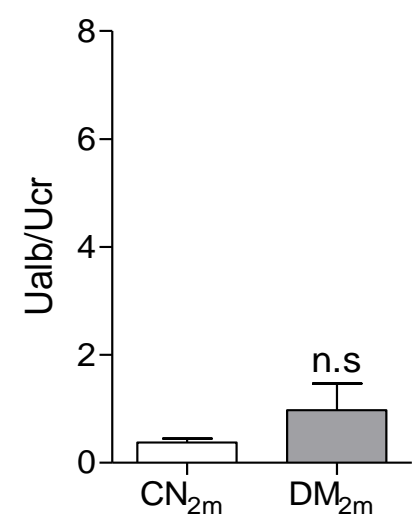

C

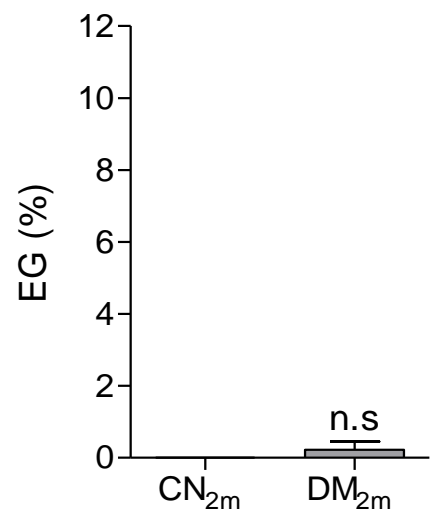

Figura 7. Concentração de glicose no sangue (Glicemia, mg/dL), albumina urinária/creatinina urinária (Ualb/Ucr) e frequência de glomérulos com lesões escleróticas (EG,\%) nos ratos controles (grupo $\mathrm{CN}_{2 m}, \mathrm{n}=5$ ) e DM (grupo $\mathrm{DM}_{2 m}, \mathrm{n}=7$ ) dois meses após a injeção de STZ, mostrados em A, B e C, respectivamente. Resultados expressos como média \pm EP. ${ }^{*} p<0,05$ vs. $\mathrm{CN}_{2 m} ;{ }^{\text {n.s. }} p>0,05$.

A

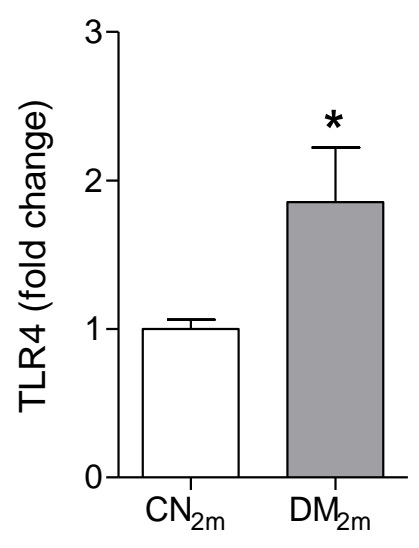

D

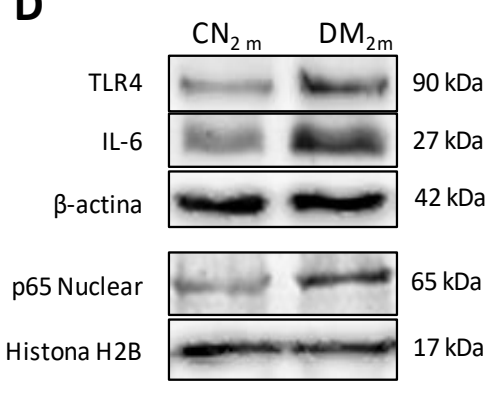

B

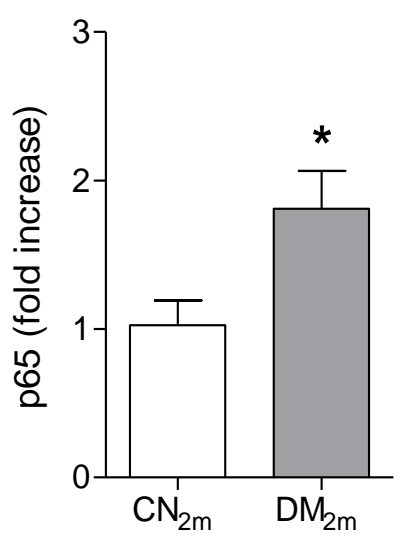

E

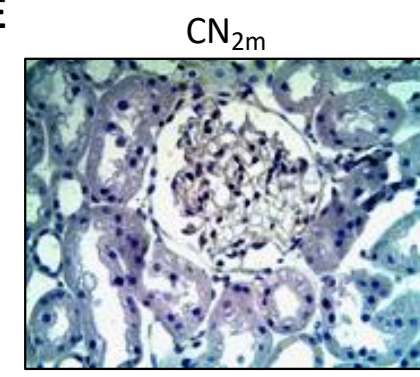

C
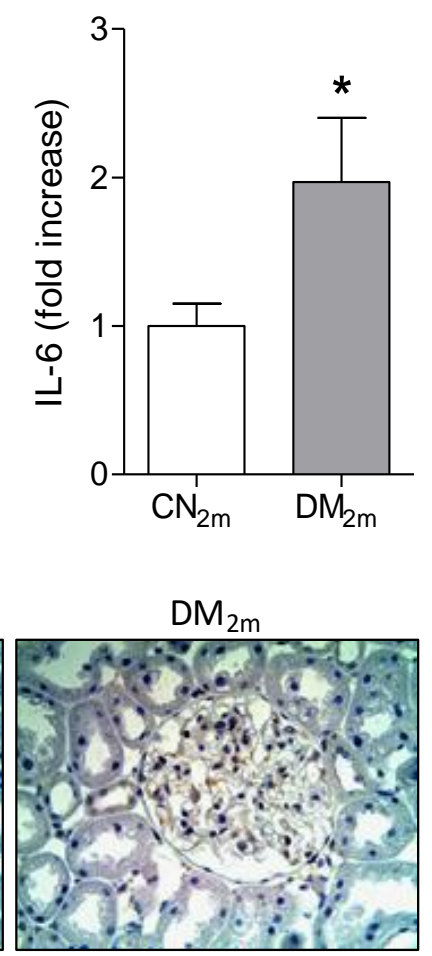

Figura 8. Os conteúdos renais de toll-like receptor 4 (TLR4, A), da fração nuclear de p65 fosforilada (B) e de interleucina-6 (IL-6, C) de ratos controles (grupo $\mathrm{CN}_{2 m}, n=5$ ) e DM (grupo $\mathrm{DM}_{2 m}, \mathrm{n}=7$ ), aos 2 meses de $\mathrm{DM}$, foram quantificados utilizando Western blot (D). Em E, microfotografias representativas mostram a presença de imunocoloração positiva para p65 (marrom) nos glomérulos (400x). Resultados expressos como média $\pm \mathrm{EP}$. ${ }^{*} \mathrm{p}<0,05$ vs. $\mathrm{CN}_{2 \mathrm{~m}}$. 


\section{Ditiocarbamato de Pirrolidina inibiu a via do NF-kB e preveniu o desenvolvimento de DRD na DM experimental}

Para verificar diretamente se o sistema NF-KB desempenha um papel na patogênese da DRD, tratamos ratos diabéticos com um inibidor do NF-KB, o PDTC, por 12 meses. O PDTC reduziu de maneira eficaz o conteúdo de TLR4, a translocação nuclear de p65 e o aumento de IL-6 e HMGB1 (Figura 9A-E) no tecido renal, sem exercer efeito sobre o peso ou a glicemia (Figura 10A-B).

A

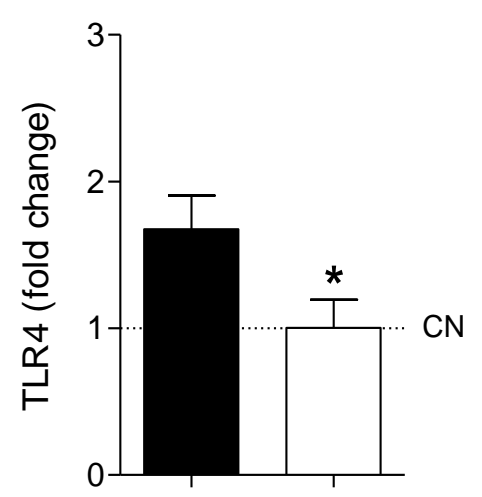

D

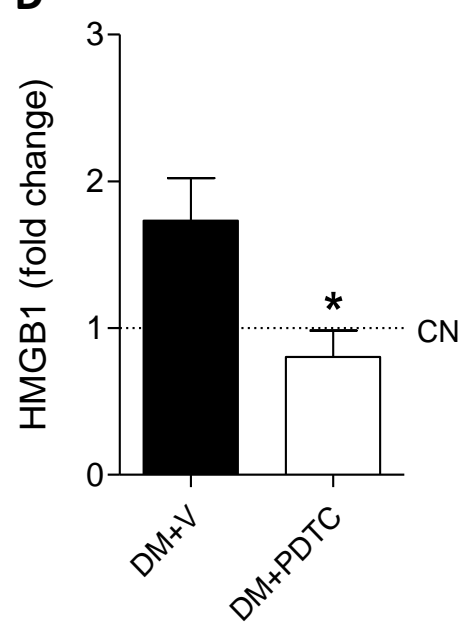

B

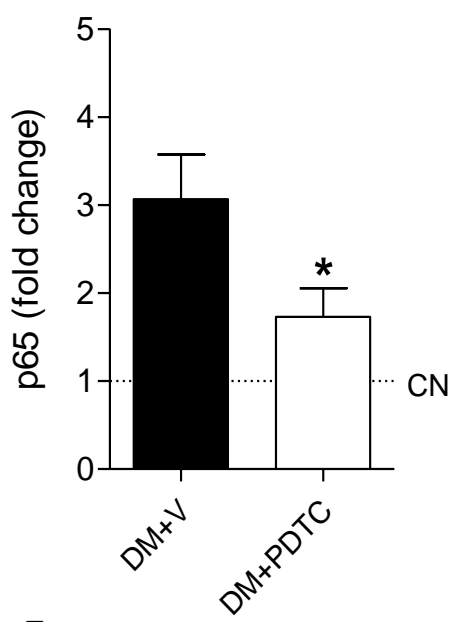

$E$

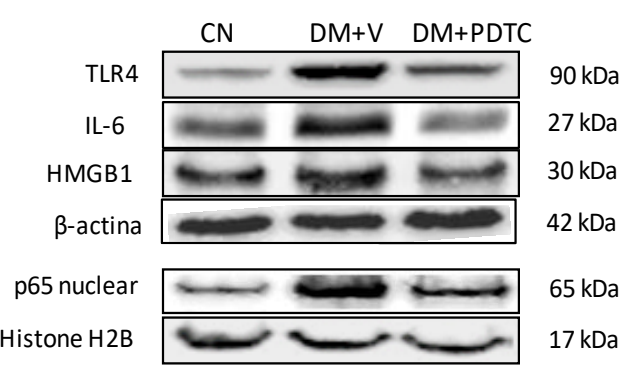

Figura 9. Ratos DM tratados com ditiocarbamato de pirrolidina (grupo DM+PDTC, $n=11$ ) ou veículo ( $\mathrm{DM}+\mathrm{V}, \mathrm{n}=16$ ) foram acompanhados por 12 meses. No final desse período, os conteúdos renais de toll-like receptor 4 (TLR4, A), da fração nuclear de p65 fosforilada (B), de interleucina 6 (IL-6, C) e da high mobility group box protein-1 (HMGB1, D) foram quantificados por Western blot (E). Os valores obtidos nos grupos DM+V e DM+PDTC foram fatorados pelo valor obtido em ratos controles ( $\mathrm{CN}$, linhas pontilhadas horizontais). Resultados expressos como média $\pm \mathrm{EP} .{ }^{*} \mathrm{p}<0,05$ vs. $\mathrm{DM}+\mathrm{V}$. 
A

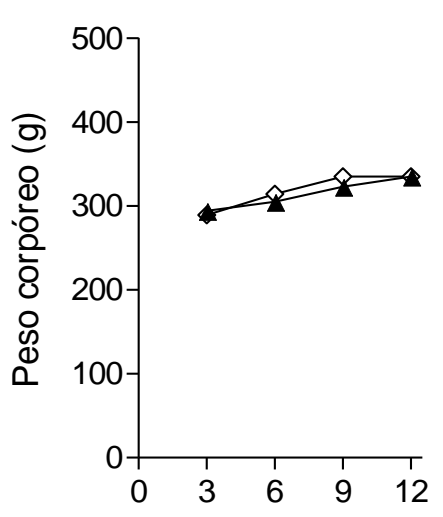

B

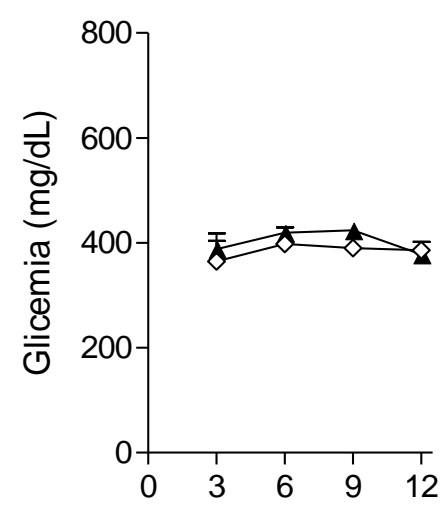

C

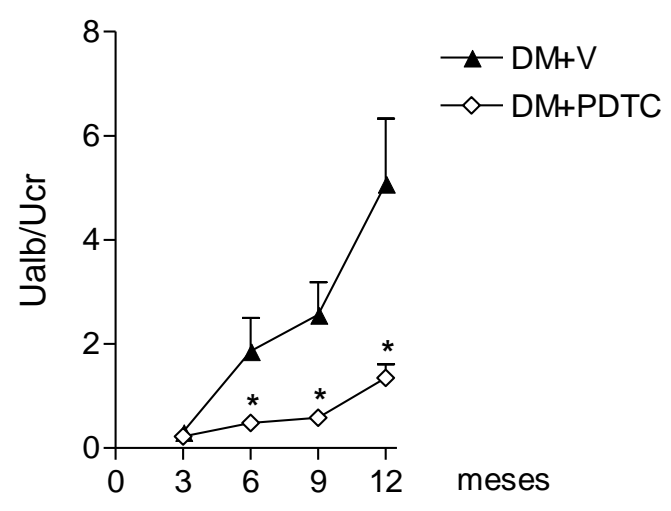

Figura 10. Evolução temporal do peso corpóreo (A), da glicemia (B) e da relação albumina/creatinina urinária (Ualb/Ucr, C) em ratos tratados com ditiocarbamato de pirrolidina (Grupo DM+PDTC, $n=11$ ) ou veículo (Grupo $D M+V, n=16$ ) durante 12 meses. Resultados expressos como média $\pm \mathrm{EP} .{ }^{*} \mathrm{p}<0,05 \mathrm{vs}$. DM+V.

O PDTC inibiu o sistema NF-kB e protegeu de modo eficaz os animais diabéticos do aumento progressivo da albuminúria (Figura 10C), bem como do desenvolvimento de glomeruloesclerose, da perda de ZO-1 e da infiltração glomerular por macrófagos (Figura 11A-D). 
A

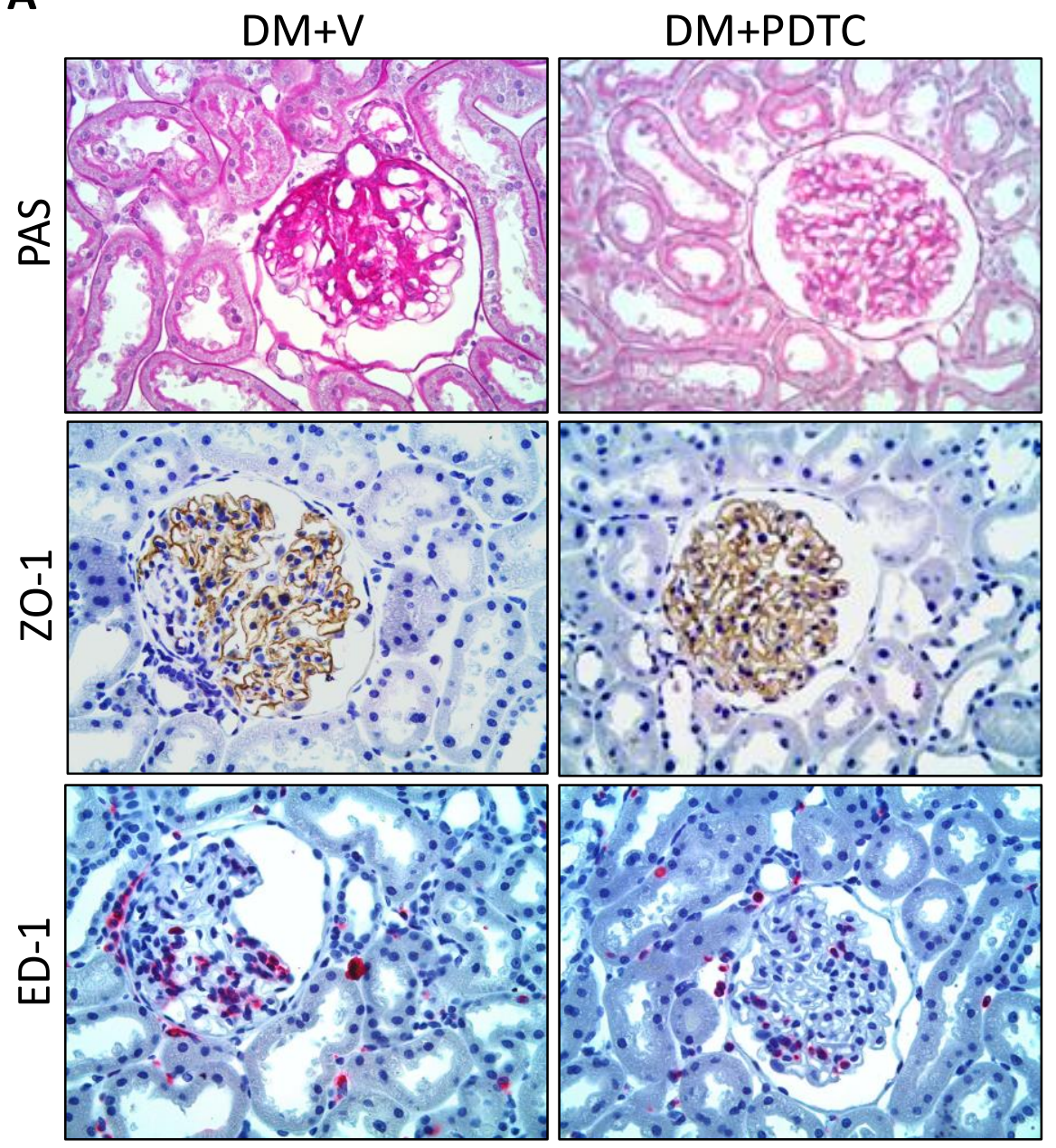

B

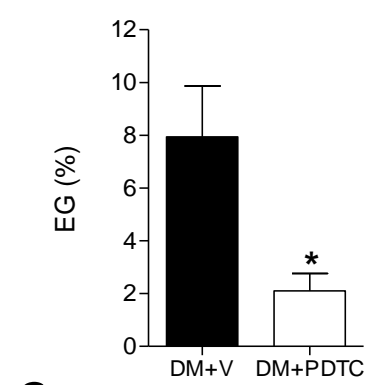

C

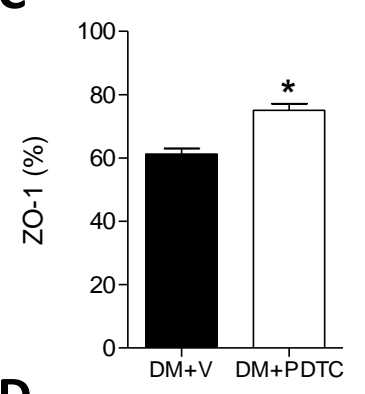

D

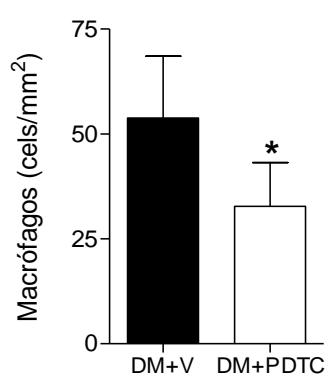

Figura 11. Em A, microfotografias ilustrativas $(x 400)$ da glomeruloesclerose e da detecção, por imuno-histoquímica, de zonula occludens-1 (ZO-1) (marrom) e macrófagos (ED-1) (vermelho) na área glomerular de ratos tratados com ditiocarbamato de pirrolidina (Grupo DM+PDTC, $n=11$ ) ou veículo (Grupo DM+V, $n=16$ ) aos 12 meses de DM. Quantificação da freqüência de glomérulos com lesões escleróticas ( $E G, B)$, da área glomerular positiva para ZO-1 (C) e da densidade de macrófagos (ED-1, D) nos glomérulos ao fim de 12 meses de DM. Resultados expressos como média \pm EP. ${ }^{*} p<0,05$ vs. $D M+V$.

O PDTC também restaurou a abundância de HO-1 e SOD2 no tecido renal, indicando que o estresse oxidativo foi reduzido pelo tratamento (Figura $12 A-C)$. 
A

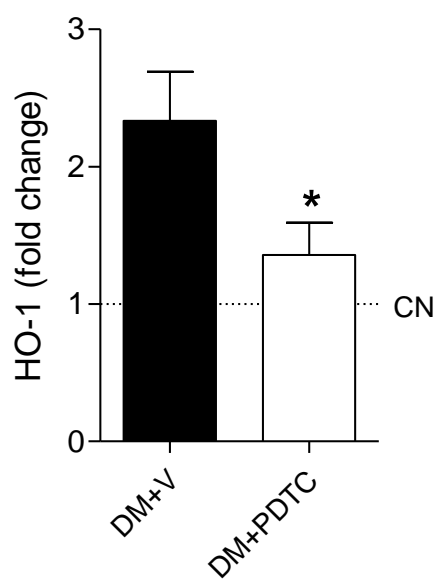

B

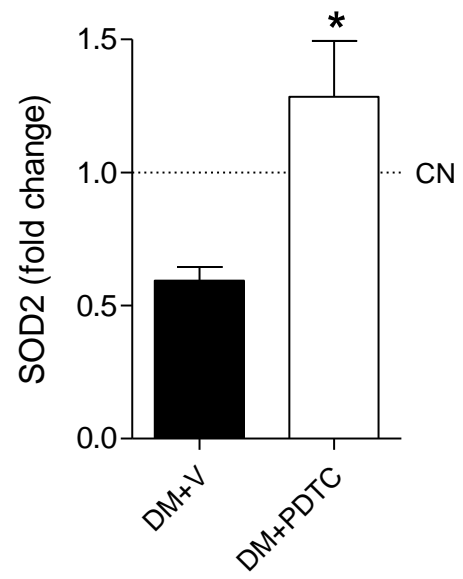

C

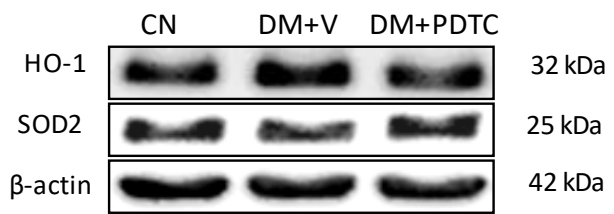

Figura 12. Conteúdo renal de heme oxigenase-1 (HO-1, A) e de superóxido dismutase 2 (SOD2, B), quantificado por análise de Western blot (C) em ratos tratados com ditiocarbamato de pirrolidina (Grupo DM+PDTC, $n=11$ ) ou veículo (Grupo DM+V), aos 12 meses de DM. Os valores obtidos nos grupos DM+V e DM+PDTC foram fatorados pelo valor obtido em ratos controles ( $\mathrm{CN}$, linhas pontilhadas horizontais). Resultados expressos como média $\pm \mathrm{EP} .{ }^{*} \mathrm{p}<0,05$ vs. $\mathrm{DM}+\mathrm{V}$.

\section{O sistema NF-KB está ativado também na DRD humana}

A análise imuno-histoquímica do tecido renal de pacientes com DM Tipo 1 e DRD revelou intensa marcação positiva para p65 ao redor dos nódulos de

Kimmestiel-Wilson, bem como em áreas intersticiais inflamadas. No rim normal saudável, a marcação foi confinada a uns poucos perfis tubulares (Figura 13). 


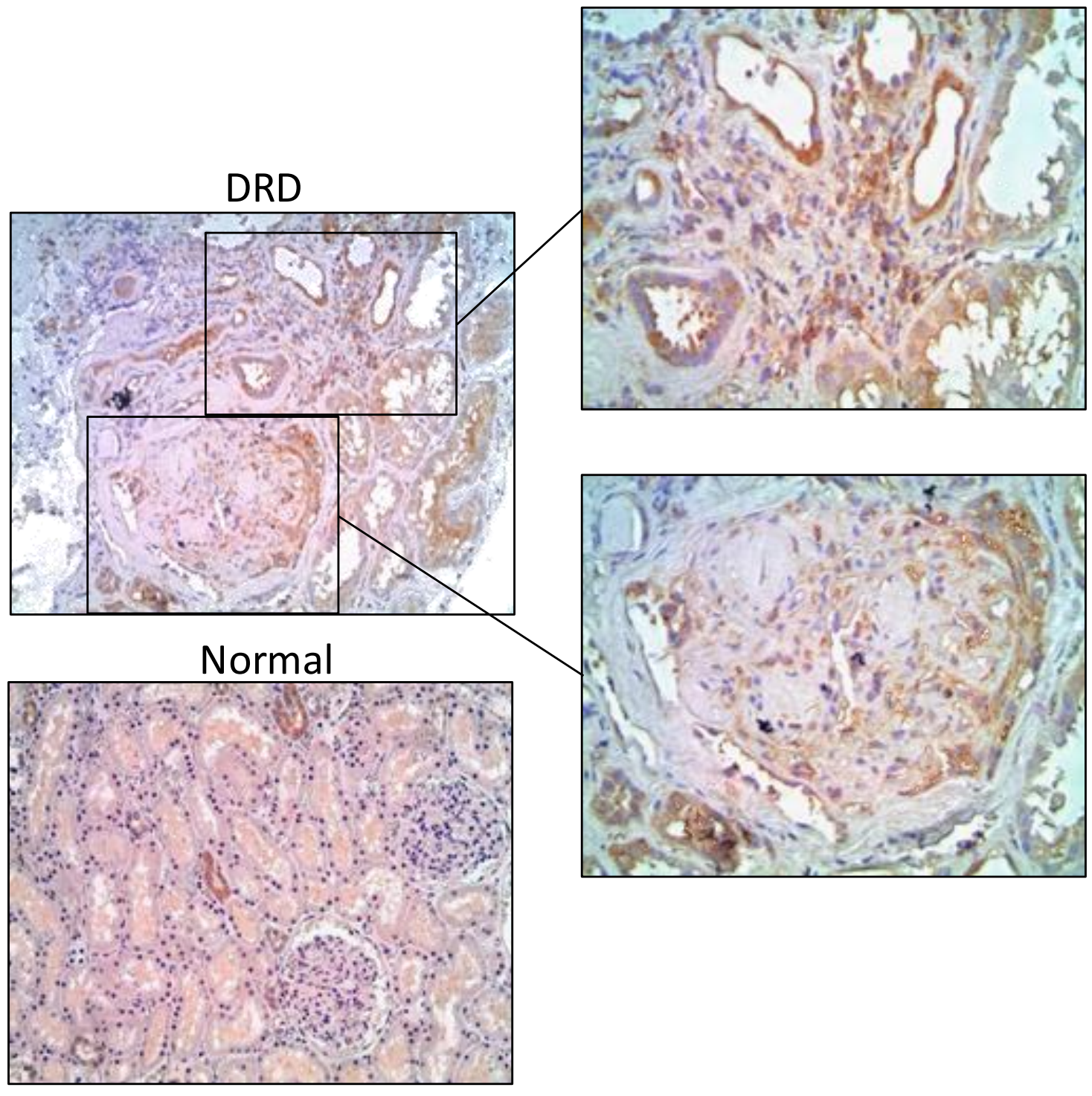

Figura 13. Microfotografias representativas do tecido renal de um paciente diabético tipo 1 com doença renal avançada, com imuno-histoquímica para p65 (marrom), detectada ao redor dos nódulos de Kimmestiel-Wilson e nas áreas intersticiais inflamadas, enquanto no tecido renal normal apenas perfis tubulares dispersos foram corados. Ampliação: x200 (fotografias principais) e x400 (inserções). 


\section{DISCUSSÃO}

Como já demonstrado em estudos anteriores $(20,50,51)$, ratos mantidos moderadamente hiperglicêmicos apresentaram aumento progressivo da albuminúria e desenvolveram glomeruloesclerose após um ano de DM. Apesar da diferença significativa de \%EG entre $\mathrm{CN}$ e DM, uma grande dispersão de valores foi observada, a tal ponto que dois subgrupos - progressores e nãoprogressores - puderam ser formados com base na presença de lesões glomerulares esclerosantes. Essa distribuição mimetiza a situação encontrada na prática clínica, na qual apenas uma fração dos pacientes diabéticos - entre 20 e $40 \%(55,56)$ - desenvolve DRD ao longo do tempo. Comparando esses dois subgrupos, nós pudemos detectar diferenças que ocorreram de forma independente do desarranjo metabólico desses animais, uma vez que a glicemia foi mantida aproximadamente a mesma entre progressores e nãoprogressores ao longo do estudo.

Apesar dos níveis similares de glicose no sangue, apenas o subgrupo progressor exibiu ativação da via NF-KB, indicada pelo aumento da expressão renal de TLR4, de p65 nuclear e da proteína-alvo IL-6. Essas alterações ocorreram em paralelo com um aumento significativo da infiltração de macrófagos nos glomérulos. É importante ressaltar que a abundância renal de NLRP3 não se mostrou aumentada nos progressores, indicando que, diferentemente do NF-KB, a via do inflamassoma não estava ativada nesses animais.

Observações anteriores de nosso grupo e de outros (57) demonstraram que o sistema NF-kB renal é ativado nos modelos de DRC por ablação renal (47, 
58), por sobrecarga de adenina na dieta (59) e por administração de doxorrubicina (45). Consistentemente, a inibição do NF-KB com PDTC atenuou a lesão e a inflamação renal em dois desses modelos experimentais $(47,59)$. Evidências recentes sugerem que a ativação do NF-KB pode também participar da patogênese da DRD. Já foi demonstrado que altos níveis de glicose induzem a ativação do TLR/NF-KB e aumentam a produção de citocinas próinflamatórias (31). A ativação do NF-kB pode resultar da ligação de AGEs aos seus receptores específicos, os RAGEs (60-62). Em podócitos expostos a elevadas concentrações de glicose, a expressão de TLR4 e de MCP-1 foi aumentada através de uma via dependente de NF-kB (63), enquanto a infiltração de macrófagos e a produção de angiotensina II foram atenuadas pelo tratamento com PDTC em um modelo animal de curto prazo de DM (49). A hipertensão capilar glomerular e o resultante stretching mecânico das células glomerulares, um conhecido fator patogênico (64), podem ser potencializados pela concomitante exposição a altas concentrações de glicose, promovendo inflamação via ativação do NF-kB (65).

No presente estudo, foi demonstrado que a ativação do NF-KB já ocorre após dois meses da injeção de STZ, em um momento no qual a albuminúria ainda é insignificante e as lesões escleróticas glomerulares são indetectáveis por microscopia óptica. Esse achado sugere que no modelo de DM por STZ, a ativação do NF-KB é um evento precoce, que precede o desenvolvimento de inflamação glomerular e que deve participar da patogênese da glomeruloesclerose. É concebível que os ratos que exibem maior translocação nuclear de p65 nesse momento são aqueles destinados a desenvolver DRD no 
futuro, mas o presente estudo não provê dados que apoiem diretamente esse conceito.

O tratamento crônico com PDTC inibiu eficientemente a ativação do sistema NF-KB e reduziu a produção de IL-6 no tecido renal aos doze meses de diabetes. É interessante notar que o PDTC também preveniu o aumento na expressão renal de TLR4 pelo DM. O mecanismo responsável por esse efeito não é evidente. Entretanto, pode-se notar que a expressão de HMGB1, também aumentada no grupo diabético, foi igualmente inibida pelo tratamento com PDTC. O HMGB1 é um ligante do TLR4 e, ao mesmo tempo, é um produto da ativação do NF-KB $(31,66)$. Portanto, o aumento da produção de HMGB1 pelo NF-KB pode resultar no estabelecimento de um feedback positivo, que pode contribui para a extensão e perpetuação da inflamação renal (43). Pode ter sido esse o mecanismo interrompido pelo tratamento com PDTC.

O PDTC protegeu os animais diabéticos contra o aumento progressivo da albuminúria, o desenvolvimento de glomeruloesclerose, a perda da integridade dos podócitos (estimada pela expressão de ZO-1) e a infiltração glomerular por macrófagos observada após um ano de diabetes. Esse efeito renoprotetor do PDTC não está relacionado a alterações da glicemia, mas pode ser atribuído à eficiente inibição do NF-kB promovida pelo composto. Um possível mecanismo adicional para o efeito salutar do PDTC é a melhora do estresse oxidativo, sugerida pela restauração do conteúdo renal de HO-1 e SOD2 $(45,58)$. Essa ação antioxidante do PDTC já foi demonstrada em outros modelos de DRC (59, 67). Uma vez que a ativação do NF-KB pode aumentar o estresse oxidativo (68), que por sua vez ativa o próprio sistema NF-KB, um feedback positivo, análogo ao postulado para o HMGB1 (43), pode surgir (69), contribuindo 
também para a natureza progressiva da nefropatia. Ao interromper mais esse ciclo vicioso, o PDTC pode prevenir a instalação de lesões glomerulares e o desenvolvimento de DRD nesses animais diabéticos.

Verzola e colaboradores (2014) recentemente detectaram, por imunohistoquímica, a proteína p65 em glomérulos lesados de pacientes com DM tipo 2 e DRD avançada (70). No presente estudo, nós detectamos esse componente do NF-KB também em glomérulos de pacientes com DM tipo 1 e DRD avançada. Em ambos os estudos, a proteína p65 também se revelou presente em áreas inflamadas do interstício renal. Uma vez que no presente estudo e em estudos anteriores de DM em ratos a inflamação (64) e a ativação do NF-kB foram confinadas aos glomérulos, a identificação de p65 no interstício desses pacientes com DRD avançada sugere que o processo todo se inicia nos glomérulos e se propaga para a área intersticial em fases mais avançadas. De qualquer forma, esses achados sugerem que a ativação do NFKB desempenha um importante papel patogênico na DRD experimental, assim como na doença humana. 


\section{CONCLUSÕES}

Nossas observações indicam que:

- Na diabetes por STZ, o sistema NF-KB é ativado seletivamente nos glomérulos, e apenas nos ratos que desenvolvem DRD;

- A ativação do NF-KB precede 0 desenvolvimento de glomeruloesclerose nos animais diabéticos;

- A inibição crônica do NF-KB protege os rins do estresse oxidativo e do desenvolvimento de inflamação/lesões glomerulares;

- O sistema NF-KB pode se tornar um importante alvo terapêutico no esforço para prevenir a progressão da DRD humana. 


\section{REFERÊNCIAS}

1. Reutens AT, Atkins RC. Epidemiology of diabetic nephropathy. Contributions to nephrology. 2011;170:1-7.

2. Sesso RC, Lopes AA, Thomé FS, Lugon JR, Martins CT. Brazilian Chronic Dialysis Survey 2016. J Bras Nefrol. 2017;39(3):261-6.

3. Cohen AJ, McGill PD, Rossetti RG, Guberski DL, Like AA. Glomerulopathy in spontaneously diabetic rat. Impact of glycemic control. Diabetes. 1987;36(8):944-51.

4. Petersen J, Ross J, Rabkin R. Effect of insulin therapy on established diabetic nephropathy in rats. Diabetes. 1988;37(10):1346-50.

5. The effect of intensive treatment of diabetes on the development and progression of long-term complications in insulin-dependent diabetes mellitus. The Diabetes Control and Complications Trial Research Group. The New England journal of medicine. 1993;329(14):977-86.

6. The relationship of glycemic exposure $(\mathrm{HbA} 1 \mathrm{c})$ to the risk of development and progression of retinopathy in the diabetes control and complications trial. Diabetes. 1995;44(8):968-83.

7. Nakamura T, Fukui M, Ebihara I, Osada S, Nagaoka I, Tomino Y, et al. mRNA expression of growth factors in glomeruli from diabetic rats. Diabetes. 1993;42(3):450-6.

8. Rocco MV, Chen Y, Goldfarb S, Ziyadeh FN. Elevated glucose stimulates TGF-beta gene expression and bioactivity in proximal tubule. Kidney international. 1992;41(1):107-14.

9. Di Paolo S, Gesualdo L, Ranieri E, Grandaliano G, Schena FP. High glucose concentration induces the overexpression of transforming growth factor-beta through the activation of a platelet-derived growth factor loop in human mesangial cells. The American journal of pathology. 1996;149(6):2095106.

10. Brownlee M, Cerami A. The biochemistry of the complications of diabetes mellitus. Annual review of biochemistry. 1981;50:385-432.

11. Mayer TK, Freedman ZR. Protein glycosylation in diabetes mellitus: a review of laboratory measurements and of their clinical utility. Clinica chimica acta; international journal of clinical chemistry. 1983;127(2):147-84.

12. Gonzalez I, Romero J, Rodriguez BL, Perez-Castro R, Rojas A. The immunobiology of the receptor of advanced glycation end-products: trends and challenges. Immunobiology. 2013;218(5):790-7. 
13. Flyvbjerg A, Denner L, Schrijvers BF, Tilton RG, Mogensen TH, Paludan SR, et al. Long-term renal effects of a neutralizing RAGE antibody in obese type 2 diabetic mice. Diabetes. 2004;53(1):166-72.

14. Forbes JM, Fukami K, Cooper ME. Diabetic nephropathy: where hemodynamics meets metabolism. Experimental and clinical endocrinology \& diabetes : official journal, German Society of Endocrinology [and] German Diabetes Association. 2007;115(2):69-84.

15. Clements RS, Jr., Morrison AD, Winegrad AI. Polyol pathway in aorta: regulation by hormones. Science. 1969;166(3908):1007-8.

16. Zatz R, Meyer TW, Rennke HG, Brenner BM. Predominance of hemodynamic rather than metabolic factors in the pathogenesis of diabetic glomerulopathy. Proc Natl Acad Sci U S A. 1985;82(17):5963-7.

17. Ditzel J, Schwartz M. Abnormally increased glomerular filtration rate in short-term insulin-treated diabetic subjects. Diabetes. 1967;16(4):264-7.

18. Mogensen CE. Glomerular filtration rate and renal plasma flow in longterm juvenile diabetics without proteinuria. British medical journal. 1972;4(5835):257-9.

19. Hostetter TH, Troy JL, Brenner BM. Glomerular hemodynamics in experimental diabetes mellitus. Kidney international. 1981;19(3):410-5.

20. Zatz R, Dunn BR, Meyer TW, Anderson S, Rennke HG, Brenner BM. Prevention of diabetic glomerulopathy by pharmacological amelioration of glomerular capillary hypertension. The Journal of clinical investigation. 1986;77(6):1925-30.

21. Young BA, Johnson RJ, Alpers CE, Eng E, Gordon K, Floege J, et al. Cellular events in the evolution of experimental diabetic nephropathy. Kidney international. 1995;47(3):935-44.

22. Sassy-Prigent C, Heudes D, Mandet C, Belair MF, Michel O, Perdereau $\mathrm{B}$, et al. Early glomerular macrophage recruitment in streptozotocin-induced diabetic rats. Diabetes. 2000;49(3):466-75.

23. Utimura R, Fujihara CK, Mattar AL, Malheiros DM, Noronha IL, Zatz R. Mycophenolate mofetil prevents the development of glomerular injury in experimental diabetes. Kidney international. 2003;63(1):209-16.

24. Anders HJ, Lech M. NOD-like and Toll-like receptors or inflammasomes contribute to kidney disease in a canonical and a non-canonical manner. Kidney Int. 2013;84(2):225-8.

25. Goncalves GM, Castoldi A, Braga TT, Camara NO. New roles for innate immune response in acute and chronic kidney injuries. Scandinavian journal of immunology. 2011;73(5):428-35. 
26. Couser WG. Basic and translational concepts of immune-mediated glomerular diseases. Journal of the American Society of Nephrology : JASN. 2012;23(3):381-99.

27. Anders HJ, Banas B, Schlondorff D. Signaling danger: toll-like receptors and their potential roles in kidney disease. Journal of the American Society of Nephrology : JASN. 2004;15(4):854-67.

28. $\mathrm{Yu} \mathrm{L}$, Wang L, Chen S. Endogenous toll-like receptor ligands and their biological significance. J Cell Mol Med. 2010;14(11):2592-603.

29. Creagh EM, O'Neill LA. TLRs, NLRs and RLRs: a trinity of pathogen sensors that co-operate in innate immunity. Trends in immunology. 2006;27(8):352-7.

30. Li F, Yang N, Zhang L, Tan H, Huang B, Liang Y, et al. Increased expression of toll-like receptor 2 in rat diabetic nephropathy. American journal of nephrology. 2010;32(2):179-86.

31. Lin M, Yiu WH, Wu HJ, Chan LY, Leung JC, Au WS, et al. Toll-like receptor 4 promotes tubular inflammation in diabetic nephropathy. J Am Soc Nephrol. 2012;23(1):86-102.

32. Cha JJ, Hyun YY, Lee MH, Kim JE, Nam DH, Song HK, et al. Renal protective effects of toll-like receptor 4 signaling blockade in type 2 diabetic mice. Endocrinology. 2013;154(6):2144-55.

33. Wang C, Pan Y, Zhang QY, Wang FM, Kong LD. Quercetin and allopurinol ameliorate kidney injury in STZ-treated rats with regulation of renal NLRP3 inflammasome activation and lipid accumulation. PloS one. 2012;7(6):e38285.

34. Sen $R$, Baltimore D. Multiple nuclear factors interact with the immunoglobulin enhancer sequences. Cell. 1986;46(5):705-16.

35. Ruiz-Ortega M, Bustos C, Hernandez-Presa MA, Lorenzo O, Plaza JJ, Egido J. Angiotensin II participates in mononuclear cell recruitment in experimental immune complex nephritis through nuclear factor-kappa B activation and monocyte chemoattractant protein-1 synthesis. J Immunol. 1998;161(1):430-9.

36. Nabel G, Baltimore D. An inducible transcription factor activates expression of human immunodeficiency virus in $\mathrm{T}$ cells. Nature. 1987;326(6114):711-3.

37. O'Neill LA, Kaltschmidt C. NF-kappa B: a crucial transcription factor for glial and neuronal cell function. Trends Neurosci. 1997;20(6):252-8.

38. Lan Q, Mercurius KO, Davies PF. Stimulation of transcription factors NF kappa B and AP1 in endothelial cells subjected to shear stress. Biochem Biophys Res Commun. 1994;201(2):950-6. 
39. Gloire G, Legrand-Poels S, Piette J. NF-kappaB activation by reactive oxygen species: fifteen years later. Biochemical pharmacology. 2006;72(11):1493-505.

40. Small DM, Coombes JS, Bennett N, Johnson DW, Gobe GC. Oxidative stress, anti-oxidant therapies and chronic kidney disease. Nephrology (Carlton). 2012;17(4):311-21.

41. Henkel T, Machleidt T, Alkalay I, Kronke M, Ben-Neriah Y, Baeuerle PA. Rapid proteolysis of I kappa B-alpha is necessary for activation of transcription factor NF-kappa B. Nature. 1993;365(6442):182-5.

42. Barnes PJ, Karin M. Nuclear factor-kappaB: a pivotal transcription factor in chronic inflammatory diseases. The New England journal of medicine. 1997;336(15):1066-71.

43. van Beijnum JR, Buurman WA, Griffioen AW. Convergence and amplification of toll-like receptor (TLR) and receptor for advanced glycation end products (RAGE) signaling pathways via high mobility group B1 (HMGB1). Angiogenesis. 2008;11(1):91-9.

44. Mezzano SA, Barria M, Droguett MA, Burgos ME, Ardiles LG, Flores C, et al. Tubular NF-kappaB and AP-1 activation in human proteinuric renal disease. Kidney international. 2001;60(4):1366-77.

45. Faustino VD, Arias SCA, Ávila VF, Foresto-Neto O, Zambom FFF, Machado FG, et al. Simultaneous activation of innate and adaptive immunity participates in the development of renal injury in a model of heavy proteinuria. Biosci Rep. 2018.

46. Schreck R, Meier B, Männel DN, Dröge W, Baeuerle PA. Dithiocarbamates as potent inhibitors of nuclear factor kappa B activation in intact cells. J Exp Med. 1992;175(5):1181-94.

47. Fujihara CK, Antunes GR, Mattar AL, Malheiros DM, Vieira JM, Zatz R. Chronic inhibition of nuclear factor-kappaB attenuates renal injury in the 5/6 renal ablation model. Am J Physiol Renal Physiol. 2007;292(1):F92-9.

48. Okabe C, Borges RL, de Almeida DC, Fanelli C, Barlette GP, Machado FG, et al. NF-kappaB activation mediates crystal translocation and interstitial inflammation in adenine overload nephropathy. American journal of physiology Renal physiology. 2013;305(2):F155-63.

49. Lee FT, Cao Z, Long DM, Panagiotopoulos S, Jerums G, Cooper ME, et al. Interactions between angiotensin II and NF-kappaB-dependent pathways in modulating macrophage infiltration in experimental diabetic nephropathy. J Am Soc Nephrol. 2004;15(8):2139-51.

50. Fujihara CK, Padilha RM, Zatz R. Glomerular abnormalities in long-term experimental diabetes. Role of hemodynamic and nonhemodynamic factors and effects of antihypertensive therapy. Diabetes. 1992;41(3):286-93. 
51. Teles F, Machado FG, Ventura BH, Malheiros DM, Fujihara CK, Silva LF, et al. Regression of glomerular injury by losartan in experimental diabetic nephropathy. Kidney Int. 2009;75(1):72-9.

52. Mancini G, Carbonara AO, Heremans JF. Immunochemical quantitation of antigens by single radial immunodiffusion. Immunochemistry. 1965;2(3):23554.

53. Fujihara CK, Avancini Costa Malheiros DM, de Lourdes Noronha II, De Nucci G, Zatz R. Mycophenolate Mofetil Reduces Renal Injury in the Chronic Nitric Oxide Synthase Inhibition Model. Hypertension. 2001;37(1):170-5.

54. Wallenstein S, Zucker CL, Fleiss JL. Some statistical methods useful in circulation research. Circulation research. 1980;47(1):1-9.

55. Molitch ME, DeFronzo RA, Franz MJ, Keane WF, Mogensen CE, Parving $\mathrm{HH}$, et al. Nephropathy in diabetes. Diabetes care. 2004;27 Suppl 1:S79-83.

56. Gross JL, de Azevedo MJ, Silveiro SP, Canani LH, Caramori ML, Zelmanovitz T. Diabetic nephropathy: diagnosis, prevention, and treatment. Diabetes care. 2005;28(1):164-76.

57. Rangan G, Wang Y, Harris D. NF-kappaB signalling in chronic kidney disease. Front Biosci (Landmark Ed). 2009;14:3496-522.

58. Foresto-Neto O, Ávila VF, Arias SCA, Zambom FFF, Rempel LCT, Faustino VD, et al. NLRP3 inflammasome inhibition ameliorates tubulointerstitial injury in the remnant kidney model. Lab Invest. 2018.

59. Okabe C, Borges RL, de Almeida DC, Fanelli C, Barlette GP, Machado $F G$, et al. NF-kB activation mediates crystal translocation and interstitial inflammation in adenine overload nephropathy. Am J Physiol Renal Physiol. 2013;305(2):F155-63.

60. Yan SD, Schmidt AM, Anderson GM, Zhang J, Brett J, Zou YS, et al. Enhanced cellular oxidant stress by the interaction of advanced glycation end products with their receptors/binding proteins. J Biol Chem. 1994;269(13):988997.

61. Doi T, Vlassara H, Kirstein M, Yamada Y, Striker GE, Striker LJ. Receptor-specific increase in extracellular matrix production in mouse mesangial cells by advanced glycosylation end products is mediated via platelet-derived growth factor. Proc Natl Acad Sci U S A. 1992;89(7):2873-7.

62. Wendt TM, Tanji N, Guo J, Kislinger TR, Qu W, Lu Y, et al. RAGE drives the development of glomerulosclerosis and implicates podocyte activation in the pathogenesis of diabetic nephropathy. Am J Pathol. 2003;162(4):1123-37.

63. Wei M, Li Z, Xiao L, Yang Z. Effects of ROS-relative NF-kB signaling on high glucose-induced TLR4 and MCP-1 expression in podocyte injury. Mol Immunol. 2015;68(2 Pt A):261-71. 
64. Utimura R, Fujihara CK, Mattar AL, Malheiros DM, Noronha IL, Zatz R, et al. Mycophenolate mofetil prevents the development of glomerular injury in experimental diabetes. Kidney Int. 2003;63(1):209-16.

65. Gruden G, Setti G, Hayward A, Sugden D, Duggan S, Burt D, et al. Mechanical stretch induces monocyte chemoattractant activity via an NFkappaB-dependent monocyte chemoattractant protein-1-mediated pathway in human mesangial cells: inhibition by rosiglitazone. J Am Soc Nephrol. 2005;16(3):688-96.

66. Wang $Y$, Zhong J, Zhang X, Liu Z, Yang Y, Gong Q, et al. The Role of HMGB1 in the Pathogenesis of Type 2 Diabetes. $J$ Diabetes Res. 2016;2016:2543268.

67. Yang $\mathrm{P}$, Li Y, Xu G. Antioxidant therapy improves non-thyroidal illness syndrome in uremic rats. Ren Fail. 2016;38(4):514-20.

68. Anrather J, Racchumi G, ladecola C. NF-kappaB regulates phagocytic NADPH oxidase by inducing the expression of gp91phox. J Biol Chem. 2006;281(9):5657-67.

69. Morgan MJ, Liu ZG. Crosstalk of reactive oxygen species and NF-kB signaling. Cell Res. 2011;21(1):103-15.

70. Verzola D, Cappuccino L, D'Amato E, Villaggio B, Gianiorio F, Mij M, et al. Enhanced glomerular Toll-like receptor 4 expression and signaling in patients with type 2 diabetic nephropathy and microalbuminuria. Kidney Int. $2014 ; 86(6): 1229-43$. 
ARTIGOS PUBLICADOS DURANTE O PROGRAMA DE DOUTORADO 


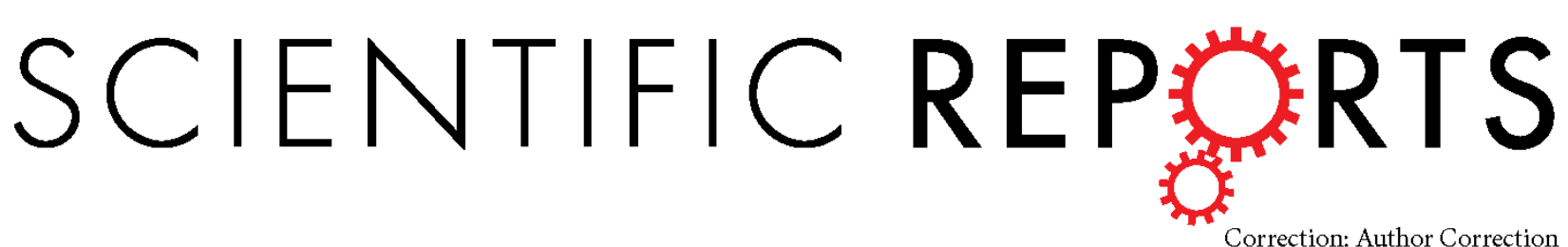

Correction: Author Correction

\section{OPEN Particles of different sizes and shapes induce neutrophil necroptosis followed by the release of neutrophil extracellular trap-like chromatin}

Received: 30 June 2017

Accepted: 20 October 2017

Published online: 03 November 2017
Jyaysi Desai ${ }^{1}$, Orestes Foresto-Neto ${ }^{1}$, Mohsen Honarpisheh ${ }^{1}$, Stefanie Steiger ${ }^{1}$, Daigo Nakazawa ${ }^{1}$, Bastian Popper ${ }^{2}$, Eva Miriam Buhl ${ }^{3,4}$, Peter Boor $\varpi^{3}$, Shrikant R. Mulay ${ }^{1}$ \& Hans-Joachim Anders ${ }^{1}$

The human body is exposed to a wide range of particles of industrial, environmental or internal origin such as asbestos, alum, silica or crystals of urate, calcium phosphate, calcium oxalate, cystine or cholesterol. Phagocytic clearance of such particles involves neutrophils and macrophages. Here we report that neutrophils encountering such particles of diverse sizes and shapes undergo necrotic cell death, a process associated with the formation of neutrophil extracellular trap (NET)-like extracellular DNA. In human neutrophils receptor-interacting protein kinase (RIPK)-1 inhibition with necrostatin-1s or mixed lineage kinase domain-like (MLKL) inhibition with necrosulfonamide abrogated cell death and associated-neutrophil extracellular DNA release induced by all of the aforementioned particles. Similar results were obtained with $M l k l$-deficient mice neutrophils for all particles in vitro. Furthermore, $M l k l$ deficient mice lacked tophus formation upon injection of MSU crystals into subcutaneous air pouches. These findings imply that nano- or microparticle-induced neutrophil extracellular DNA release is the consequence of neutrophil necroptosis, a regulated form of cell necrosis defined by RIPK1-RIPK3MLKL signaling. Interestingly, this finding was consistent across different particle sizes and shapes. The RIPK1-RIPK3-MLKL signaling pathway may represent a potential therapeutic target in nano- or microparticle-related diseases (crystallopathies).

The human body is frequently exposed to microparticles from different sources. Air-borne particulates, smoking, and occupational dusts enter the respiratory tract and expose bronchial and lung cells. Cosmetic products and certain drug carriers are enriched with industrial particles that reach external and internal epithelial barriers. In addition, microparticles, fibrils or crystals form from misfolded proteins inside the body. Finally, minerals or intrinsic metabolites form crystals upon supersaturation in excretory organs such as the biliary, salivary or urinary tracts. Usually, phagocytes clear extracellular material by phagocytic uptake and lysosomal digestion, a process that may fail, if such particles are indigestible or whenever size or shape do not allow phagocytic uptake. The consequence of clearance failure of particles is tissue inflammation and of needle-shaped or large particles is foreign body granuloma formation presenting as acute or chronic 'crystallopathies', respectively'.

Neutrophils are the most abundant phagocytes in the blood and patrol through all tissues to clear them from bacteria, cell debris or other microparticles. Bacterial killing can involve direct phagocytosis or neutrophil extracellular trap (NET) formation, a process that immobilizes bacteria via expulsion of nuclear and mitochondrial DNA, kills bacteria by the release of histones and cytoplasmic proteases, and awaits phagocytic removal of

${ }^{1}$ Medizinische Klinik und Poliklinik IV, Klinikum der Universität München, Munich, Germany. ${ }^{2}$ Department of Anatomy and Cell Biology, Biomedical Center, Ludwig-Maximilians Universität, Munich, Germany. ${ }^{3}$ Institut für Pathologie, Universitätsklinikum Aachen, Aachen, Germany. ${ }^{4}$ Institute of Pathology \& Department of Nephrology, University Clinic of the RWTH Aachen, Aachen, Germany. Correspondence and requests for materials should be addressed to H.-J.A. (email: hjanders@med.uni-muenchen.de) 


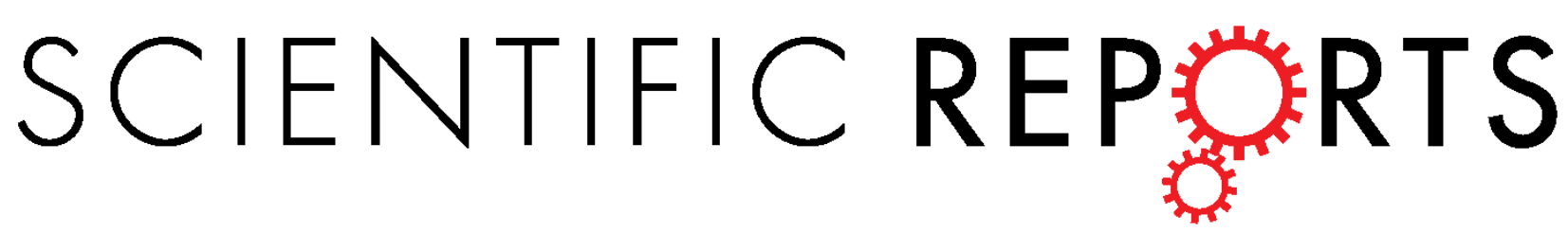

Received: 21 March 2017

Accepted: 2 November 2017

Published online: 14 November 2017
Phagocytosis of environmental or metabolic crystalline particles induces cytotoxicity by triggering necroptosis across a broad range of particle size and shape

Mohsen Honarpisheh ${ }^{1}$, Orestes Foresto-Neto ${ }^{1}$, Jyaysi Desai ${ }^{1}$, Stefanie Steiger ${ }^{1}$, Lidia Anguiano Gómez ${ }^{1}$, Bastian Popper ${ }^{2}$, Peter Boor $\mathbb{D}^{3}$, Hans-Joachim Anders ${ }^{1}$ \& Shrikant R. Mulay ${ }^{1}$

In crystallopathies, crystals or crystalline particles of environmental and metabolic origin deposit within tissues, induce inflammation, injury and cell death and eventually lead to organ-failure. The NLRP3inflammasome is involved in mediating crystalline particles-induced inflammation, but pathways leading to cell death are still unknown. Here, we have used broad range of intrinsic and extrinsic crystalor crystalline particle-sizes and shapes, e.g. calcium phosphate, silica, titanium dioxide, cholesterol, calcium oxalate, and monosodium urate. As kidney is commonly affected by crystallopathies, we used human and murine renal tubular cells as a model system. We showed that all of the analysed crystalline particles induce caspase-independent cell death. Deficiency of MLKL, siRNA knockdown of RIPK3, or inhibitors of necroptosis signaling e.g. RIPK-1 inhibitor necrostatin-1s, RIPK3 inhibitor dabrafenib, and MLKL inhibitor necrosulfonamide, partially protected tubular cells from crystalline particles cytotoxicity. Furthermore, we identify phagocytosis of crystalline particles as an upstream event in their cytotoxicity since a phagocytosis inhibitor, cytochalasin D, prevented their cytotoxicity. Taken together, our data confirmed the involvement of necroptosis as one of the pathways leading to cell death in crystallopathies. Our data identified RIPK-1, RIPK3, and MLKL as molecular targets to limit tissue injury and organ failure in crystallopathies.

Crystals of intrinsic or extrinsic origin induce inflammation and tissue injury when deposited inside the body triggering diverse medical disorders termed as "crystallopathies" e.g. occupational dust-induced lung injuries ${ }^{1-3}$ (silica crystals and titanium dioxide $\left(\mathrm{TiO}_{2}\right.$ ) nanoparticles), various forms of crystal nephropathies ${ }^{1,4,5}$ (crystals of calcium oxalate $(\mathrm{CaOx})$, monosodium urate (MSU), and calcium phosphate $(\mathrm{CaP})$ ), gouty arthritis ${ }^{1,6}$ (MSU crystals), atherosclerosis 1,7 (cholesterol crystals). These crystallopathies are characterized by crystal-induced acute necroinflammation ${ }^{1,8,9}$. Although the capability of crystals and crystalline materials to induce NOD-like receptor protein (NLRP)- 3 inflammasome-mediated interleukin (IL)-1 $\beta$, IL-18 release, and subsequent inflammation gained importance as a major pathomechanism of these crystallopathies ${ }^{10}$, their cytotoxic effects have remained poorly explored. Crystals induce cell necrosis rather than apoptosis ${ }^{11,12}$. However, it has remained unclear whether crystal cytotoxicity is a consequence of passive or regulated necrosis until recently when we reported that intrinsic $\mathrm{CaOx}$ crystal deposition induces receptor interacting protein kinase-3 (RIPK3) - mixed lineage kinase domain-like (MLKL)-mediated necroptosis in tubular epithelial cells during acute oxalate nephropathy ${ }^{8}$. Since, $\mathrm{CaOx}$ crystals can also activate the NLRP 3 inflammasome ${ }^{13}$ in a similar manner as it is reported for crystals of silica ${ }^{14,15}$, cholesterol ${ }^{16}, \mathrm{MSU}^{17}, \mathrm{CaP}^{18}$ and $\mathrm{TiO}_{2}$ nanoparticles ${ }^{19}$, therefore, we here hypothesized

${ }^{1}$ Medizinische Klinik und Poliklinik IV, Klinikum der Universität, München, Munich, 80336, Germany. ${ }^{2}$ Biomedical Center (BMC), Department for Cell Biology, Ludwig-Maximilians University, Munich, 82152, Germany. ${ }^{3}$ Institute of Pathology \& Dept. of Nephrology, University Clinic of RWTH Aachen, Aachen, 52074, Germany. Hans-Joachim Anders and Shrikant R. Mulay contributed equally to this work. Correspondence and requests for materials should be addressed to H.-J.A. (email: hjanders@med.uni-muenchen.de) or S.R.M. (email: Shrikant_Ramesh.Mulay@med. uni-muenchen.de) 


\title{
The macrophage phenotype and inflammasome component NLRP3 contributes to nephrocalcinosis- related chronic kidney disease independent from IL-1-mediated tissue injury
}

\author{
Hans-Joachim Anders ${ }^{1,4}$, Beatriz Suarez-Alvarez ${ }^{1,4}$, Melissa Grigorescu ${ }^{1,4}$, Orestes Foresto-Neto 1,4, \\ Stefanie Steiger', Jyaysi Desai', Julian A. Marschner', Mohsen Honarpisheh', Chongxu Shi', \\ Jutta Jordan², Lisa Müller, Nicolai Burzlaff ${ }^{3}$, Tobias Bäuerle² and Shrikant R. Mulay
}

${ }^{1}$ Medizinische Klinik und Poliklinik $N$, Klinikum der Universität, Ludwig-Maximilians-Universität München, Munich, Germany; ${ }^{2}$ Predinical Imaging Platform Erlangen, Institute of Radiology, Friedrich-Alexander-Universität Erlangen-Nürnberg, Erlangen, Germany; and ${ }^{3}$ Department of Chemistry and Pharmacy, Inorganic Chemistry and Interdisciplinary Center for Molecular Materials, Friedrich-AlexanderUniversität Erlangen-Nürnberg, Erlangen, Germany

Primary/secondary hyperoxalurias involve nephrocalcinosis-related chronic kidney disease (CKD) leading to end-stage kidney disease. Mechanistically, intrarenal calcium oxalate crystal deposition is thought to elicit inflammation, tubular injury and atrophy, involving the NLRP3 inflammasome. Here, we found that mice deficient in NLRP3 and ASC adaptor protein failed to develop nephrocalcinosis, compromising conclusions on nephrocalcinosis-related CKD. In contrast, hyperoxaluric wild-type mice developed profound nephrocalcinosis. NLRP3 inhibition using the $\beta$-hydroxybutyrate precursor 1,3-butanediol protected such mice from nephrocalcinosisrelated CKD. Interestingly, the IL-1 inhibitor anakinra had no such effect, suggesting IL-1-independent functions of NLRP3. NLRP3 inhibition using 1,3-butanediol treatment induced a shift of infiltrating renal macrophages from pro-inflammatory $\left(\mathrm{CD} 45^{+} \mathrm{F} 4\right.$ / $\left.80^{+} \mathrm{CD} 11 \mathrm{~b}^{+} \mathrm{CX} 3 \mathrm{CR} 1^{+} \mathrm{CD} 206\right)$ and pro-fibrotic (CD45 ${ }^{+} \mathrm{F} 4 /$ $\left.80^{+} \mathrm{CD} 11 \mathrm{~b}^{+} \mathrm{CX} 3 \mathrm{CR} 1{ }^{+} \mathrm{CD} 206^{+} \mathrm{TGF}^{+}\right)$to an antiinflammatory $\left(\mathrm{CD} 45^{+} \mathrm{F} 4 / 80^{+} \mathrm{CD} 11 \mathrm{~b}^{+} \mathrm{CD} 206^{+} \mathrm{TGF} \beta\right)$ phenotype, and prevented renal fibrosis. Finally, in vitro studies with primary murine fibroblasts confirmed the nonredundant role of NLRP3 in the TGF- $\beta$ signaling pathway for fibroblast activation and proliferation independent of the NLRP3 inflammasome complex formation. Thus, nephrocalcinosis-related CKD involves NLRP3 but not necessarily via intrarenal IL-1 release but rather via other biological functions including TGFR signaling and macrophage polarization. Hence, NLRP3 may be a promising therapeutic target in hyperoxaluria and nephrocalcinosis.

Correspondence: Shrikant Ramesh Mulay, Medizinische Klinik und Poliklinik IV, Klinikum der Universität München, Schillerstrasse 42, 80336 München, Germany.E-mail: shrikant_ramesh.mulay@med.uni-muenchen.de

${ }^{4} \mathrm{H}-J \mathrm{~A}, \mathrm{BS}-\mathrm{A}, \mathrm{MG}$, and OF-N contributed equally to this article.

Received 31 May 2017; revised 12 September 2017; accepted 21 September 2017; published online 12 December 2017
Kidney International (2018) 93, 656-669; https://doi.org/10.1016/ j.kint.2017.09.022

KEYWORDS: beta-hydroxybutyrate; crystal nephropathy; fibrosis; NALP3; necroinflammation

Copyright (c) 2017, International Society of Nephrology. Published by Elsevier Inc. This is an open access article under the CC BY-NC-ND license (http://creativecommons.org/licenses/by-nc-nd/4.0/).

3 rimary/secondary hyperoxalurias are characterized by increased serum and urine levels of oxalate, which promote calcium oxalate $(\mathrm{CaOx})$ crystal formation and deposition in the kidney, i.e., nephrocalcinosis. ${ }^{1,2}$. Progressive nephrocalcinosis is associated with nephron loss, renal fibrosis, and renal failure, i.e., chronic kidney disease (CKD) progressing to end-stage kidney disease. ${ }^{1-3}$ The traditional disease concept of hyperoxaluria-induced nephrocalcinosis involves supersaturation of oxalate and calcium in the urinary lumen of the renal tubules, which, in the absence of sufficient amounts of crystallization inhibitors, causes intraluminal CaOx crystal formation. ${ }^{3,4}$ Tubular obstruction following crystal-plug formation traditionally has been considered the dominant pathomechanism of tubular injury, but recent discoveries suggest a relevant contribution of $\mathrm{CaOx}$ crystalinduced necroinflammation in kidney injury.

The NACHT, leucine-rich repeat (LRR), and pyrin effector domain (PYD) domain containing protein 3 (NLRP3) is a central molecular mediator of inflammation in acute and chronic crystallopathies. ${ }^{6,7}$ NLRP3 belongs to the nucleotidebinding oligomerization domain (Nod)-Like receptor family of pattern recognition receptors. ${ }^{8}$ It forms a complex with an apoptosis-associated speck-like protein (ASC) containing a caspase activation and recruitment domain (CARD) domain adaptor protein, and the cysteine protease caspase-1, generating an inflammasome complex. Upon activation of caspase1 , this complex mediates the maturation of the pro-inflammatory cytokines ${ }^{8,9}$ interleukin (IL) $-1 \beta$ and IL-18. Crystals activate the NLRP3 inflammasome via phagocytosis, $\mathrm{K}^{+}$efflux, and protease leakage from the lysosomal 


\title{
TLR2 and TLR4 play opposite role in autophagy associated with cisplatin-induced acute kidney injury
}

\author{
Magaiver Andrade-Silva ${ }^{1, *}$, Marcos Antonio Cenedeze ${ }^{2, *}$, Luiz Augusto Perandini ${ }^{1}$, Raphael \\ José Ferreira Felizardo ${ }^{1}$, Ingrid Kazue Mizuno Watanabe ${ }^{2}$, Juan Sebastian Henao Agudelo ${ }^{2}$, Angela Castoldi ${ }^{1}$, \\ Giselle Martins Gonçalves ${ }^{1}$, Clarice Silvia Taemi Origassa ${ }^{2}$, Patricia Semedo ${ }^{2}$, Meire loshie Hiyane ${ }^{1}$, \\ Orestes Foresto-Neto ${ }^{3}$, Denise Maria Avancini Costa Malheiros ${ }^{4}$, Marlene Antonia Reis ${ }^{5}$, \\ Clarice Kazue Fujihara ${ }^{3}$, Roberto Zatz ${ }^{3}$, Alvaro Pacheco-Silva ${ }^{2}$, Niels Olsen Saraiva Câmara ${ }^{1,2}$ and \\ Danilo Candido de Almeida ${ }^{1,2}$
}

${ }^{1}$ Department of Immunology, Universidade de São Paulo, São Paulo, Brazil ; ${ }^{2}$ Department of Medicine, Nephrology Division, Universidade Federal de São Paulo, São Paulo, Brazil ${ }^{3}$ Renal Division, Department of Clinical Medicine, Faculty of Medicine, Universidade de São Paulo, Brazil; ${ }^{4}$ Department of Medicine, Renal Pathology, Universidade de São Paulo, São Paulo, Brazil; ${ }^{5}$ Department of Biomedical Sciences, Universidade Federal do Triângulo Mineiro, Uberaba, Brazil

Correspondence: Niels 0lsen Saraiva Câmara (niels@icb.usp.br) or Danilo Candido de Almeida (d.almeida@unifesp.br)

* These authors have contributed equally to this work.

Received: 28 March 2017 Revised: 15 February 2018 Accepted: 02 March 2018

Accepted Manuscript Online: 02 March 2018

Version of Record published: 22 August 2018
Acute kidney injury (AKI) is considered an inflammatory disease in which toll-like receptors (TLRs) signaling pathways play an important role. The activation of TLRs results in production of several inflammatory cytokines leading to further renal damage. In contrast, TLRs are key players on autophagy induction, which is associated with a protective function on cisplatin-induced AKI. Hence, the present study aimed to evaluate the specific participation of TLR2 and TLR4 molecules on the development of cisplatin-induced AKI. Complementarily, we also investigated the link between TLRs and heme oxygenase-1 $(\mathrm{HO}-1)$, a promisor cytoprotective molecule. First, we observed that only the absence of TLR2 but not TLR4 in mice exacerbated the renal dysfunction, tissue injury and mortality rate, even under an immunologically privileged microenvironment. Second, we demonstrated that TLR2 knockout (KO) mice presented lower expression of autophagy-associated markers when compared with TLR4 KO animals. Similar parameter was confirmed in vitro, using tubular epithelial cells derived from both $\mathrm{KO}$ mice. To test the cross-talking between $\mathrm{HO}-1$ and $\mathrm{TLRs}$, hemin (an $\mathrm{HO}-1$ internal inducer) was administrated in cisplatin-treated TLR2 and TLR4 KO mice and it was detected an improvement in the global renal tissue parameters. However, this protection was less evident at TLR2 KO mice. In summary, we documented that TLR2 plays a protective role in cisplatin-induced AKI progression, in part, by a mechanism associated with autophagy up-regulation, considering that its interplay with $\mathrm{HO}-1$ can promote renal tissue recover.

\section{Introduction}

Acute kidney injury (AKI) is considered a severe syndrome with progressive and cumulative damage affecting million people worldwide. Currently, many investigators have described the impact of inflammation on AKI development [1-3]. However, the precise role of innate immune response such as the participation of toll-like receptors (TLRs) family in different sets of AKI manifestation remains partially elucidated [4,5]. These specific molecules act as vigilante agents decoding exogenous/endogenous signals, which are released by cell death, inflammation, or stress [6,7]. 


\title{
NLRP3 inflammasome inhibition ameliorates tubulointerstitial injury in the remnant kidney model
}

\author{
Orestes Foresto-Neto ${ }^{1} \cdot$ Victor Ferreira Ávila ${ }^{1} \cdot$ Simone Costa Alarcon Arias ${ }^{1}$. \\ Fernanda Florencia Fregnan Zambom ${ }^{1} \cdot$ Lisienny Campoli Tono Rempel ${ }^{1}$. Viviane Dias Faustino ${ }^{1}$. \\ Flavia Gomes Machado ${ }^{1}$. Denise Maria Avancini Costa Malheiros ${ }^{1} \cdot$ Hugo Abensur ${ }^{1} \cdot$ Niels Olsen Saraiva Camara $^{1,2}$. \\ Roberto Zatz ${ }^{1} \cdot$ Clarice Kazue Fujihara ${ }^{1}$
}

Received: 29 September 2017 / Revised: 6 December 2017 / Accepted: 2 January 2018

(c) United States \& Canadian Academy of Pathology 2018

\begin{abstract}
Recent studies suggest that NLRP3 inflammasome activation is involved in the pathogenesis of chronic kidney disease (CKD). Allopurinol (ALLO) inhibits xanthine oxidase (XOD) activity, and, consequently, reduces the production of uric acid (UA) and reactive oxygen species (ROS), both of which can activate the NLRP3 pathway. Thus, ALLO can contribute to slow the progression of CKD. We investigated whether inhibition of XOD by ALLO reduces NLRP3 activation and renal injury in the 5/6 renal ablation $(\mathrm{Nx})$ model. Adult male Munich-Wistar rats underwent $\mathrm{Nx}$ and were subdivided into the following two groups: $\mathrm{Nx}$, receiving vehicle only, and $\mathrm{Nx}+\mathrm{ALLO}, \mathrm{Nx}$ rats given ALLO, $36 \mathrm{mg} / \mathrm{Kg} / \mathrm{day}$ in drinking water. Rats undergoing sham operation were studied as controls (C). Sixty days after surgery, Nx rats exhibited marked albuminuria, creatinine retention, and hypertension, as well as glomerulosclerosis, tubular injury, and cortical interstitial expansion/inflammation/fibrosis. Such changes were accompanied by increased XOD activity and UA renal levels, associated with augmented heme oxigenase- 1 and reduced superoxide dismutase- 2 renal contents. Both the NF- $\mathrm{KB}$ and NLRP3 signaling pathways were activated in Nx. ALLO normalized both XOD activity and the parameters of oxidative stress. ALLO also attenuated hypertension and promoted selective tubulointerstitial protection, reducing urinary NGAL and cortical interstitial injury/inflammation. ALLO reduced renal NLRP3 activation, without interfering with the NF- $\mathrm{KB}$ pathway. These observations indicate that the tubulointerstitial antiinflammatory and antifibrotic effects of ALLO in the Nx model involve inhibition of the NLRP3 pathway, and reinforce the view that ALLO can contribute to arrest or slow the progression of CKD.
\end{abstract}

\section{Introduction}

Chronic kidney disease (CKD) is a worldwide health problem with high rates of mortality and need for renal replacement therapy. Early intervention against risk factors involved in the pathogenesis of CKD is crucial to avoid the

\footnotetext{
$\triangle$ Orestes Foresto-Neto forestoneto@usp.br

$\triangle$ Roberto Zatz

roberto.zatz@gmail.com

1 Renal Division, Department of Clinical Medicine, Faculty of Medicine, University of São Paulo, São Paulo, Brazil

2 Laboratory of Transplantation Immunobiology, Institute of Biomedical Sciences, University of São Paulo, São Paulo, Brazil
}

progression of the disease. CKD is characterized by progressive proteinuria, hypertension, chronic inflammation and oxidative stress that lead to loss of renal function and fibrosis. Recently we showed that renal inflammasome activation occurs as early as fifteen days after $5 / 6$ renal ablation $(\mathrm{Nx})$, and persists through advanced phases of this CKD model [1]. Additional recent observations suggest that renal inflammasome is activated in patients with CKD and in animal models of this condition [2-5], and that its deficiency prevents kidney injury [6].

The Nucleotide-binding oligomerization domain, Leucine-rich Repeat and Pyrin domain containing-3 (NLRP3) belongs to the NLR family of pattern recognition receptors. It forms a complex with Apoptosisassociated Speck-like protein containing a Caspase recruitment domain adaptor protein (ASC), and the caspase 1 protease to generate a multiprotein inflammasome complex, 


\title{
Simultaneous activation of innate and adaptive immunity participates in the development of renal injury in a model of heavy proteinuria
}

\author{
Viviane Dias Faustino ${ }^{1}$, Simone Costa Alarcon Arias ${ }^{1}$, Victor Ferreira Ávila ${ }^{1}$, Orestes Foresto-Neto ${ }^{1}$, Fernanda \\ Florencia Fregnan Zambom ${ }^{1}$, Flavia Gomes Machado ${ }^{1}$, Luciene Machado dos Reis ${ }^{1}$, Denise Maria \\ Avancini Costa Malheiros ${ }^{1}$, Rildo Aparecido Volpini ${ }^{1}$, Niels Olsen Saraiva Camara ${ }^{1,2}$, Roberto Zatz ${ }^{1}$ and \\ Clarice Kazue Fujihara ${ }^{1}$
}

${ }^{1}$ Renal Division, Department of Clinical Medicine, Faculty of Medicine, University of São Paulo, São Paulo, Brazil; '2Laboratory of Transplantation Immunobiology, Institute of Biomedical Sciences, University of Säo Paulo, São Paulo, Brazil

Correspondence: Roberto Zat (roberto.zatz@gmail.com) or Viviane Dias Faustino (vianedias@hotmail.com)

\section{OPEN ACCESS}

Received: 04 April 2018 Revised: 11 June 2018 Accepted: 18 June 2018

Accepted Manuscript Online: 18 June 2018

Version of Record published: 13 July 2018
Protein overload of proximal tubular cells (PTCs) can promote interstitial injury by unclear mechanisms that may involve activation of innate immunity. We investigated whether prolonged exposure of tubular cells to high protein concentrations stimulates innate immunity, triggering progressive interstitial inflammation and renal injury, and whether specific inhibition of innate or adaptive immunity would provide renoprotection in an established model of massive proteinuria, adriamycin nephropathy (ADR). Adult male Munich-Wistar rats received a single dose of ADR ( $5 \mathrm{mg} / \mathrm{kg}$, iv), being followed for 2, 4, or 20 weeks. Massive albuminuria was associated with early activation of both the NF-kB and NLRP3 innate immunity pathways, whose intensity correlated strongly with the density of lymphocyte infiltration. In addition, ADR rats exhibited clear signs of renal oxidative stress. Twenty weeks after ADR administration, marked interstitial fibrosis, glomerulosclerosis, and renal functional loss were observed. Administration of mycophenolate mofetil (MMF), $10 \mathrm{mg} / \mathrm{kg} /$ day, prevented activation of both innate and adaptive immunity, as well as renal oxidative stress and renal fibrosis. Moreover, MMF treatment was associated with shifting of $\mathrm{M}$ from the $\mathrm{M} 1$ to the $\mathrm{M} 2$ phenotype. In cultivated NRK52-E cells, excess albumin increased the protein content of Toll-like receptor (TLR) 4 (TLR4), NLRP3, MCP-1, IL6, IL-1 $\beta$, Caspase-1, $\alpha$-actin, and collagen-1. Silencing of TLR4 and/or NLRP3 mRNA abrogated this proinflammatory/profibrotic behavior. Simultaneous activation of innate and adaptive immunity may be key to the development of renal injury in heavy proteinuric disease. Inhibition of specific components of innate and/or adaptive immunity may be the basis for future strategies to prevent chronic kidney disease (CKD) in this setting.

\section{Introduction}

Chronic kidney disease (CKD) is a growing cause of deaths and morbidity worldwide. Measures to delay the progression of CKD to end-stage renal disease are currently limited, and new strategies are needed $[1,2]$.

Tubulointerstitial inflammation plays a central role in the pathogenesis of CKD, but the exact mechanisms behind these effects remain largely unknown [3-5]. A number of in vivo and in vitro studies have provided evidence that not only proteinuria is a hallmark of kidney disease, but also that excessive protein reabsorption is a pathogenic factor involved in the development of CKD, leading proximal tubular cells 
Received: 8 February 2018

Accepted: 3 August 2018

Published online: 15 August 2018
Aristolochic acid I determine the phenotype and activation of macrophages in acute and chronic kidney disease

Mohsen Honarpisheh $\left(\mathbb{D}^{1}\right.$, Orestes Foresto-Neto ${ }^{1}{ }^{1}$, Stefanie Steiger ${ }^{1}$, Franziska Kraft ${ }^{1}$, Paulina Koehler ${ }^{1}$, Ekaterina von Rauchhaupt ${ }^{1}$, Jan Potempa ${ }^{2}$, Karina Adamowicz ${ }^{2}$, Joanna Koziel ${ }^{2} \&$ Maciej Lech $\oplus^{1,2}$

Acute and chronic kidney injuries are multifactorial traits that involve various risk factors. Experimental animal models are crucial to unravel important aspects of injury and its pathophysiological mechanisms. Translating knowledge obtained from experimental approaches into clinically useful information is difficult; therefore, significant attention needs to be paid to experimental procedures that mimic human disease. Herein, we compared aristolochic acid I (AAI) acute and chronic kidney injury model with unilateral ischemic-reperfusion injury (UIRI), cisplatin (CP)- or folic acid (FA)-induced renal damage. The administration of AAI showed significant changes in serum creatinine and BUN upon CKD. The number of neutrophils and macrophages were highly increased as well as AAI-induced CKD characterized by loss of tubular epithelial cells and fibrosis. The in vitro and in vivo data indicated that macrophages play an important role in the pathogenesis of AA-induced nephropathy (AAN) associated with an excessive macrophage accumulation and an alternative activated macrophage phenotype. Taken together, we conclude that AA-induced injury represents a suitable and relatively easy model to induce acute and chronic kidney injury. Moreover, our data indicate that this model is appropriate and superior to study detailed questions associated with renal macrophage phenotypes.

Acute kidney injury (AKI) is a global pathologic condition that occurs at a high incidence in hospitalized individuals with acute illness ${ }^{1,2}$ associated with increased mortality $y^{3,4}$. AKI is characterized by tubular injury that may be replaced by new proliferating tubular epithelial cells. This process of complete recovery from AKI is still being a topic of speculation. Various studies showed that AKI is associated with increased incidence of chronic kidney disease (CKD) due to uncontrolled and unbalanced repair processes that may lead to the development of fibrosis ${ }^{5}$. Processes such as moderate inflammation are necessary for the initiation of tissue repair. On the other hand, persistent inflammatory responses result in loss of kidney function and disease progression ${ }^{6}$. Several experimental animal models of acute and chronic kidney disease mimic the human disease. Some animal models involve operative manipulation; others are induced by intervention with toxic substances that affect renal tissue. An appropriate animal model is crucial in order to prove scientific hypothesis or evaluate a new therapeutic approach. One of the best-characterized kidney injury models is ischemia reperfusion-induced injury (IRI). Ischemic damage is associated with impairment of oxygen supply and nutrient delivery to renal tissue, as well as accumulation of metabolic waste products in renal cells. As a result of injury, tubular epithelial cells die leading to further activation of innate immune responses ${ }^{7,8}$. Not only antigen presenting cells but also tubular epithelial cells were shown to participate in inflammatory responses upon activation of evolutionarily conserved pattern recognition receptors (PRRs), which detect endogenous ligands released during inflammatory cell death ${ }^{9}$. Clinically, ischemia is a leading cause of AKI and it may result from the poor cardiac condition or kidney transplantation ${ }^{10}$. Both bilateral renal ischemia reperfusion (bIR) and unilateral renal ischemia-reperfusion (uIR) are commonly

${ }^{1}$ Klinikum der Ludwig-Maximilians-Universität München, Medizinische Klinik und Poliklinik IV, Department of Nephrology, LMU Munich, Germany. ${ }^{2}$ Departments of Microbiology, Faculty of Biochemistry, Biophysics and Biotechnology, Jagiellonian University, Krakow, Poland. Mohsen Honarpisheh and Orestes Foresto-Neto contributed equally to this work. Correspondence and requests for materials should be addressed to M.L. (email: maciej.lech@ med. uni-muenchen.de) 


\section{STAT1 regulates macrophage number and phenotype and prevents renal fibrosis after ischemia/reperfusion injury}

Stephan Kemmner*, Quirin Bachmann, Stefanie Steiger, Georg Lorenz, Mohsen Honarpisheh, Orestes Foresto-Neto, Shijun Wang, Javier Carbajo-Lozoya, Verena Alt, Christian Schulte, Stefan Chmielewski, Hans A.R. Bluyssen, Uwe Heemann, Marcus Baumann, Maciej Lech, and Christoph Schmaderer Show less Authors Published Online: 07 NOV 2018 https://doi.org/10.1152/ajprenal.00004.2018

More

\section{Abstract}

TOOLS SHARE

Renal ischemia/reperfusion injury (IRI) leads to acute kidney injury or delayed allograft function which predisposes to fibrosis in the native kidney or kidney transplant. Here we investigated the role of the signal transducer and activator of transcription 1 (STAT1) in inflammatory responses following renal IRI. Our study showed that a subsequent stimulation of Janus Kinase 2/STAT1 and toll-like receptor 4 pathways led to greater STAT1 activation followed by increased cytokine transcription compared to single-pathway stimulation in murine renal tubular cells. Moreover, we observed increased activation of STAT1 under hypoxic conditions. In vivo, STAT1 ${ }^{-/}$mice displayed less acute tubular necrosis and decreased macrophage infiltration 24 hours upon renal ischemia. However, investigation of the healing phase ( 30 days upon IRI) revealed significantly more fibrosis in STAT $1^{-/}$than in wildtype kidneys. In addition, we demonstrated increased macrophage infiltration in $\mathrm{STAT}^{-/}$kidneys. Flow cytometry analysis revealed that STAT1 deficiency drives an alternatively activated macrophage phenotype, which is associated with down-regulated CD80 expression, decreased intracellular reactive oxygen species production and enhanced ability for phagocytosis. Further, we detected immunohistochemically enhanced STAT1 expression in human renal allograft biopsies with no interstitial fibrosis/tubular atrophy (IF/TA) compared to specimens with severe IF/TA without specific etiology. Thus, STAT1-activation drives macrophages towards an alternatively activated phenotype and enhances fibrogenesis indicating a potential STAT1-driven protective mechanism in tissue repair after ischemic injury.

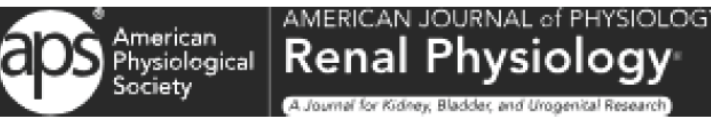

